\title{
Sediment resuspension and nepheloid layers induced by long internal solitary waves shoaling orthogonally on uniform slopes
}

\author{
D. Bourgault ${ }^{\mathrm{a}, *}$, M. Morsilli ${ }^{\mathrm{b}}$, C. Richards ${ }^{\mathrm{c}}, \mathrm{U}^{\mathrm{N}}$ Neumeier ${ }^{\mathrm{a}}$, D. E. Kelley ${ }^{\mathrm{d}}$ \\ ${ }^{a}$ Institut des sciences de la mer de Rimouski, Université du Québec à Rimouski, 310 Allée des Ursulines, Rimouski, QC, G5L 3A1, Canada \\ ${ }^{b}$ Dipartimento di Fisica e Scienze della Terra, Università di Ferrara, Via G. Saragat 1, 44100 Ferrara, Italy \\ ${ }^{c}$ Woods Hole Oceanographic Institution, 266 Woods Hole Rd, MS\# 21, Woods Hole, MA 02543-1050, USA \\ ${ }^{d}$ Dalhousie University, Department of Oceanography, 1355 Oxford Street PO BOX 15000, Halifax, NS, B3H 4R2, Canada
}

\begin{abstract}
Two-dimensional, nonlinear and nonhydrostatic field-scale numerical simulations are used to examine the resuspension, dispersal and transport of mud-like sediment caused by the shoaling and breaking of long internal solitary waves on uniform slopes. The patterns of erosion and transport are both examined, in a series of test cases with varying conditions. Shoreward sediment movement is mainly within boluses, while seaward movement is within intermediate nepheloid layers. Several relationships between properties of the suspended sediment and control parameters are determined such as the horizontal extent of the nehpeloid layers, the total mass of resuspended sediment and the point of maximum bed erosion. The numerical results provide a plausible explanation for acoustic backscatter patterns observed during and after the shoaling of internal solitary wavetrains in a natural coastal environment. The results may further help interpret sedimentary structures that may have been shaped by internal waves and add an another effective mechanism for offshore dispersal of muddy sediments.
\end{abstract}

Keywords: internal solitary wave, sediment, nepheloid layer, numerical modelling, sedimentary structures

\section{Introduction}

Long internal solitary waves (ISWs or simply waves hereafter) typically found in coastal environments are a special class of mode- 1 internal waves characterized by largeamplitude relative to the surface mixed layer thickness and high-frequency relative to the buoyancy frequency at the pycnocline (Helfrich and Melville, 2006). To give a sense of scale, in estuaries and fjords such waves may be characterized with $\sim 10 \mathrm{~m}$ amplitude, $\sim 100 \mathrm{~m}$ wavelength and $\sim 100 \mathrm{~s}$ period (e.g. Farmer and Armi, 1999; Bourgault et al., 2007) while in coastal seas, such as the South China Sea, these wave characteristics may be an order of magnitude greater with, for example, amplitude that can reach $100 \mathrm{~m}$ (e.g. Helfrich and Melville, 2006).

Internal solitary waves have emerged in recent studies as potentially effective agents for resuspending sediments in comparatively shallow environments such as coastal seas, shelves and estuaries (Bogucki et al., 1997, 2005; Bourgault et al., 2008; Carter et al., 2005; Hosegood et al., 2004; Hosegood and van Haren, 2004; Johnson et al., 2001; Klymak and Moum, 2003; Quaresma et al., 2007; Richards et al., 2013) ${ }^{1}$. Although

\footnotetext{
${ }^{*}$ Corresponding author

Email address: daniel_bourgault@uqar.ca (D. Bourgault)

${ }^{1}$ Note that for the benefit of conciseness we have excluded any discussion about internal tide and sediment resuspension. The subject is vast and the dynamic and scales of internal tide is too different from that of internal solitary waves to be treated together in a comprehensive manner in a single specialized study. This study therefore focuses only on large-amplitude and high-frequency, horizontally-propagating internal solitary waves.
}

episodic, wave-induced resuspension is hypothesized to be important enough to shape the topography and to impact coastal marine ecosystems by disturbing diagenesis processes and transporting particulate organic matter and other biologicallysensitive compounds such as iron, nutrients, or contaminants (Sandstrom and Elliott, 1984; Hosegood and van Haren, 2004; Bogucki and Redekopp, 2008; Pan et al., 2012; Pomar et al., 2012). Furthermore, recent hypotheses suggest that sediment mobilization and transport caused by internal waves in general, and internal solitary waves in particular, may be at the origin of some sedimentary structures found in the sedimentary rock record, termed internalites (Bádenas et al., 2012; Pomar et al., 2012), and also the well-known hummocky-cross stratification (Morsilli and Pomar, 2012).

While the bottom shear stress associated with stablypropagating waves may be sufficient to mobilize sediment within the wave-induced bottom boundary layer, wave destabilization and subsequent turbulence are required to efficiently propel sediment out of the bottom boundary layer and further up into the water column. To date, essentially three destabilizing mechanisms relevant to wave-induced sediment resuspension have been studied fundamentally.

One mechanism relates to the interaction of waves propagating over flat, hydrodynamically smooth bottoms and laminar boundary layer with vertically-sheared background currents. Under some conditions of background and wave characteristics, near-bottom instability and subsequent turbulence favourable for sediment resuspension may be generated, as demonstrated by two-dimensional laboratory-scale direct nu- 
merical simulations (Bogucki and Redekopp, 1999; Stastna and Lamb, 2002, 2008).

Under some conditions of stratification and wave amplitude, wave-induced boundary layer instability and vortex shedding, favourable to sediment resuspension, may also develop beneath waves propagating over flat and smooth bottoms in quiescent background environments, as demonstrated by laboratory-scale two-dimensional direct numerical simulations (Diamessis and Redekopp, 2006; Aghsaee et al., 2012) and laboratory experiments (Carr et al., 2008).

The third mechanism, of interest here, relates to wave destabilization during shoaling. As shown in laboratory and numerical experiments (Boegman and Ivey, 2009; Aghsaee et al., 2012), enhanced bottom shear stress combined with vertical velocity associated with turbulent vortices generated during wave run-up and breaking provide favorable conditions for efficient sediment resuspension and transport. Hosegood and van Haren (2004) reached similar conclusions by interpreting field measurements of shoaling waves in the Faeroe-Shetland Channel. They proposed that two factors control wave-induced sediment resuspension and transport. Firstly, vortices formed during shoaling would be responsible for bringing sediment into suspension and further upward across the density stratification, consistent with the laboratory observations described above. Secondly, turbulent boluses that are produced during shoaling (Helfrich, 1992; Bourgault et al., 2005, 2007, 2008; Venayagamoorthy and Fringer, 2007, 2012; Richards et al., 2013) would suspend and transport sediment further up the slope, where large particles may be redeposited as the boluses decay while finer particles may be advected offshore with the mixed fluid.

This view of wave-induced sediment resuspension and transport is qualitatively consistent with echo-sounder observations collected in the St. Lawrence Estuary during and after wave shoaling and breaking events (Figure 1). The top echogram shows high level of backscatter, which could be indicative of higher sediment concentration, coincident with upslope propagating boluses. The bottom echogram suggests the existence of both bottom and intermediate nepheloid layers observed approximately $30 \mathrm{~min}$ after a wavetrain shoaling event (see Richards et al., 2013, for details of this event). This intermediate nepheloid-looking layer is consistent with the idea proposed by Hosegood and van Haren (2004) of an offshore intrusion of mixed fluid charged with fine sediment. However, this is only speculation because there is no concomitant observations, such as optical backscatter measurements, to support this interpretation of the echograms. The high backscatter layers seen in the echograms could well be of other origins not related to sediment suspension (e.g. zooplankton, turbulence).

While some elements of the conceptual model proposed by Hosegood and van Haren (2004), and partly illustrated here (Figure 1), for sediment resuspension and transport caused by shoaling waves are qualitatively supported by fundamental understanding (Boegman and Ivey, 2009; Aghsaee et al., 2012), other aspects proposed remain rather speculative, lacking theories, models or laboratory experiments to rely on. For example, it is unclear what happens with the sediment thrown into the water column near the breaking depth, i.e. what is left behind after the boluses have taken their share up-slope. As already mentioned above, Hosegood and van Haren (2004) suggested that some may be carried offshore with the mixed fluid intrusion. This would then be a mechanism for the creation of intermediate nepheloid layers. Again, this has not been demonstrated fundamentally although intermediate intrusive layers are clearly reproduced with passive tracers in laboratory experiment and numerical simulations of shoaling waves (Helfrich, 1992; Bourgault et al., 2005). Another possibility is that some of the resuspended sediment end up producing internalites (Bádenas et al., 2012; Pomar et al., 2012, 2013).

In order to address some of these questions, we use here twodimensional, nonlinear, nonhydrostatic, field-scale, hydrodynamic numerical simulations coupled to a sediment model to examine idealized situations of muddy-like flocs resuspension and transport caused by shoaling internal solitary waves. The problem is complex and the parameter space too large to be fully explored in a single study. In this first effort we have made the choice of exploring a certain region of the physical parameter space, comparable to field situations, while keeping sediment parameters fixed.

\section{Methods}

\subsection{Hydrodynamic model}

Being limited by computational power, we approach the problem from a two-dimensional perspective, as done in most previous studies cited above that have addressed sediment resuspension induced by internal solitary waves. Being characterized by large-amplitudes and high-frequencies, internal solitary waves and their breaking on slopes require nonlinear and nonhydrostatic physics to be simulated, but the Coriolis force can be neglected. Simulations are therefore carried out with the two-dimensional fully nonlinear, nonhydrostatic, freesurface and Boussinesq model of Bourgault and Kelley (2004). We work under the assumption that this model captures sufficiently well the main features associated with shoaling internal solitary waves (e.g. wave steepening, flow separation, bolus formation, run-up, etc.) to draw useful conclusions. This assumption is at least partly supported with previous comparisons made between this model and laboratory measurements (Bourgault and Kelley, 2004, 2007) and field observations (see Figure 2 in Bourgault et al., 2007).

Briefly, the model solves with second-order finite differences on a $z$-coordinate stepwise topography the following equations:

$$
\begin{gathered}
\frac{\partial u}{\partial t}+\frac{\partial\left(u^{2}\right)}{\partial x}+\frac{\partial(w u)}{\partial z}=-\frac{1}{\rho_{0}} \frac{\partial p}{\partial x}+ \\
\frac{\partial}{\partial x}\left(v_{h} \frac{\partial u}{\partial x}\right)+\frac{\partial}{\partial z}\left(v_{v} \frac{\partial u}{\partial z}\right), \\
\frac{\partial w}{\partial t}+\frac{\partial(u w)}{\partial x}+\frac{\partial\left(w^{2}\right)}{\partial z}=-\frac{1}{\rho_{0}} \frac{\partial p}{\partial z}+ \\
\frac{\rho}{\rho_{0}} g+\frac{\partial}{\partial x}\left(v_{h} \frac{\partial w}{\partial x}\right)+\frac{\partial}{\partial z}\left(v_{v} \frac{\partial w}{\partial z}\right),
\end{gathered}
$$




$$
\begin{aligned}
& \frac{\partial u}{\partial x}+\frac{\partial w}{\partial z}=0 \\
& \frac{\partial \rho_{w}}{\partial t}+\frac{\partial\left(u \rho_{w}\right)}{\partial x}+\frac{\partial\left(w \rho_{w}\right)}{\partial z}= \\
& \frac{\partial}{\partial x}\left(\kappa_{h} \frac{\partial \rho_{w}}{\partial x}\right)+\frac{\partial}{\partial z}\left(\kappa_{v} \frac{\partial \rho_{w}}{\partial z}\right),
\end{aligned}
$$

where $t$ is time, $x$ and $z$ are, respectively, the along-channel and vertical axes, $u$ the horizontal velocity, $w$ the vertical velocity (positive downward), $\rho_{w}$ the density of clear water, $\rho_{0}$ a reference water density, $p$ the pressure, $v_{h}$ and $v_{v}$, respectively, the horizontal and vertical eddy viscosity and $\kappa_{h}$ and $\kappa_{v}$, respectively, the horizontal and vertical eddy diffusivity. The sea-surface height above the origin $\eta$ is obtained by integrating the continuity equation (3) and the pressure $p$ is decomposed into barotropic and baroclinic components (see Bourgault and Kelley, 2004, for details).

The equations above differ slightly from those presented in Bourgault and Kelley (2004). One difference is that the width term $B$ seen in the original paper, which permits variable domain width, is omitted here since it it taken constant (for $B=$ constant the terms cancels out). Another difference is that the advective terms have since been recoded in the flux form (i.e. given the continuity equation, advective terms such as $w \partial u / \partial z$ could be rewritten as $\partial(w u) / \partial z)$.

Unresolved subgrid-scale transport is tentatively parameterized using the Smagorinsky scheme (Smagorinsky, 1963) described in Bourgault and Kelley (2004), i.e.

$$
v_{h}= \begin{cases}\left(C_{s} \Delta x\right)^{2} \sqrt{2 S^{2}-N^{2}} & \text { if } 2 S^{2}>N^{2} \\ 10^{-6} \mathrm{~m}^{2} \mathrm{~s}^{-1} & \text { otherwise, }\end{cases}
$$

where $\Delta x$ is the horizontal grid size, $S^{2}$ is the square of the strain rate tensor (see appendix in Bourgault and Kelley (2004) for details), $N=\left(g / \rho_{0}\right) \partial \rho / \partial z$ is the buoyancy frequency and $C_{s}$ is the Smagorinsky coefficient. The vertical eddy viscosity $v_{v}$ is parameterized the same way except that the vertical grid size $\Delta z$ is used as the relevant lengthscale. Similar expressions are set for the eddy diffusivities $\kappa_{h}$ and $\kappa_{v}$ except that minimum values are set to $10^{-7} \mathrm{~m}^{2} \mathrm{~s}^{-1}$ if $2 S^{2} \leq N^{2}$. All simulations presented here use a typical value $C_{s}=0.1$ for the Smagorinsky coefficient (Table 1). We will show below that setting $C_{s}=0$ has virtually no impact on the results under consideration here and that sugbrid-scale transport is actually dominated implicitly by numerical diffusion. The sensitivity of the results to halving the grid size will be presented.

No-flux boundary conditions are applied across solid boundaries and across the sea surface. The bottom stress is discretised in a way that it converges towards the no-slip condition for $\Delta z \rightarrow 0$, using the quadratic stress formulation as it results from the law of the wall, i.e.

$$
\tau_{b} / \rho_{0}=\left.v_{v} \frac{\partial u}{\partial z}\right|_{z=H}=-C_{D}\left|u_{b}\right| u_{b},
$$

where

$$
C_{D}=\left(\frac{\kappa}{\ln \left[(\Delta z / 2) / z_{0}\right]}\right)^{2}
$$

is the drag coefficient, $u_{b}$ is the horizontal velocity in the bottom cell, $z_{0}$ is the prescribed bottom roughness length and $\kappa=0.41$ is the Von Kármán constant. Note that this approach is essentially the same as commonly used in modelling surface wave boundary layers where a logarithmic profile can be assumed to exist (e.g. Grant and Madsen, 1986; Smyth and Hay, 2002).

\subsection{Sediment model}

The sediment model is intended to represent the behaviour of single-sized cohesive mud-like flocs with constant characteristics. This is obviously a crude representation of sedimentation processes occurring in natural environments (e.g. Fettweis, 2008). As mentioned earlier, the problem we are addressing is already quite complex with the physics of breaking waves alone such that we first concentrate on the simplest situation in terms of sedimentary processes.

The model equations and boundary conditions are taken from Wang (2002) and Wang et al. (2005) and are incorporated into the hydrodynamical model described in the previous section. The main equation is for the advection-diffusion of sediment concentration $C$,

$$
\begin{array}{r}
\frac{\partial C}{\partial t}+\frac{\partial(u C)}{\partial x}+\frac{\partial\left[\left(w+w_{s}\right) C\right]}{\partial z}= \\
\frac{\partial}{\partial x}\left(\kappa_{h} \frac{\partial C}{\partial x}\right)+\frac{\partial}{\partial z}\left(\kappa_{v} \frac{\partial C}{\partial z}\right),
\end{array}
$$

where $w_{s}$ is a constant settling velocity for mud-like flocs (i.e. without flocculation influencing $w_{s}$ ).

A no-flux boundary conditions is applied across lateral solid boundaries and across the sea surface. At the bottom, the sum of the vertical advective and diffusive sediment fluxes are parameterized using the following boundary condition,

$$
\left(\kappa_{v} \frac{\partial C}{\partial z}-w_{s} C\right)_{z=H}=F_{b},
$$

where $F_{b}$ is the bottom sediment flux given by,

$$
F_{b}= \begin{cases}F_{0}\left(\left|\tau_{b}\right| / \tau_{c}-1\right) & \text { if }\left|\tau_{b}\right|>\tau_{c}, \\ C_{b} w_{s}\left(1-\left|\tau_{b}\right| / \tau_{c}\right) & \text { if }\left|\tau_{b}\right| \leq \tau_{c},\end{cases}
$$

$F_{0}$ the erosion coefficient, $C_{b}$ the sediment concentration in the bottom cell and $\tau_{c}$ the critical shear stress for sediment resuspension, assumed here equal to the critical stress for deposition for simplicity. The critical stress for deposition of cohesive sediments is generally considered different than the critical stress for resuspension (Winterwerp and Van Kesteren, 2004), however, this has virtually no impact on the results presented here because, as will be shown below, the model is not run long enough to allow significant redeposition. This boundary condition also assumes an unlimited sediment availability with constant properties.

The baroclinic pressure gradient in the hydrodynamic model is in turn affected by the presence of sediment through an adjusted equation of state that takes into account the effect of suspended sediment on water density, i.e.,

$$
\rho=\rho_{w}+\left(1-\rho_{w} / \rho_{s}\right) C,
$$


where $\rho_{s}$ is the sediment floc density. Note that simulations presented below are characterized with low sediment concentration relative to the density of clear seawater. i.e. $C / \rho_{w} \ll 1$. Sediment therefore acts almost as a passive tracer.

\subsection{Model initialization with internal solitary waves}

The model is initialized with either one or two consecutive internal solitary waves in a motionless, two-layer background environment. The initialization is done using the inviscid, fully nonlinear, steady-state, two-dimensional DubreilJacotin-Long (DJL) theory. The DJL nonlinear wave equation without background current is (Stastna and Lamb, 2002)

$$
\nabla^{2} \eta+\frac{N^{2}(z-\eta)}{c^{2}} \eta=0
$$

where $\eta(x, z)$ is the isopycnal displacement, $c$ the wave phase speed, and $N(z)$ the undisturbed background buoyancy frequency. Along with boundary conditions (i.e. $\eta=0$ at surface, bottom and $x \pm \infty$ ) and imposed available potential energy, Equation 12 is solved numerically following algorithms described in Turkington et al. (1991) and Stastna and Lamb (2002) with a source code provided by K. G. Lamb (University of Waterloo, pers. comm.). Once a solution for $\eta$ and $c$ is obtained, the density field $\rho_{w}$ as well as the horizontal and vertical currents, $u$ and $w$, can be determined from the streamfunction of the wave-induced motion (see Lamb, 2002; Stastna and Lamb, 2002, for details). Wave total mechanical energy $E_{i}$, that is the sum of wave kinetic energy and available potential energy, is obtained from this code.

\subsection{Configurations and parameter space}

The model geometry and background density conditions are loosely based on conditions similar to those prevailing in the St. Lawrence Estuary (Bourgault et al., 2007, 2008; Richards et al., 2013) and for which this model has shown good qualitative agreement with field observations for the shoaling of an internal solitary wave (Bourgault et al., 2007).

The model geometry consists of a $10 \mathrm{~km}$ long, $50 \mathrm{~m}$ deep, flat bottom section followed by a uniform shoaling boundary of slope $s$ (and therefore of angle $\theta=\tan ^{-1} s$ ) and of length $H_{\max } / s$ (Figure 2). The flat-bottom section of the numerical domain is made long enough such that any reflected wave resulting from the interaction of the initial incoming wave with the slope does not shoal a second time after reflecting off the leftward solid boundary, a problem encountered in laboratory experiments (e.g. Helfrich, 1992; Michallet and Ivey, 1999).

The horizontal grid spacing is coarse throughout most of the flat-bottom section with $\Delta x_{\max }=100 \mathrm{~m}$ but steadily increases to reach $\Delta x=1 \mathrm{~m}$ at a distance of $1 \mathrm{~km}$ from the start of the sloping boundary and further inshore (see Figure 2 for the high resolution portion of the numerical domain). The vertical resolution is $\Delta z=0.25 \mathrm{~m}$ throughout the domain. These resolutions were chosen as the compromise needed to both resolve boluses of horizontal lengthscale $\sim 10 \mathrm{~m}$ (Bourgault et al., 2007) and to obtain a large sample size for significant statistics $(\sim 30)$ covering a certain range of parameter space within a practical time frame. This horizontal resolution $\Delta x=1 \mathrm{~m}$ is also sufficiently high, relative to the depth of the pycnocline $h_{1} \sim 10 \mathrm{~m}$, for proper resolution of nonhydrostatics effects (Vitousek and Fringer, 2011). The core of the experiment consists in 36 runs listed in Table 2. Most simulations are equally distributed between the collapsing and fission shoaling mechanism regimes, except for the steep slopes simulations that fall within the plunging regime (Fig. 6 in Aghsaee et al., 2010). The first 15 experiments were repeated with two consecutive and identical waves. A few more simulations were carried out to test the sensitivity of the results to grid resolution and to the subgrid-scale parameterization. The simulations presented here requires roughly one year of computer time if they were to be run sequentially on a single modern desktop processor.

The timestep is adaptive i.e. it uses the Courant-FriedrichsLewy conditions to adjust every time step according to

$$
\Delta t=\frac{1}{3} \min \left(\frac{\Delta x}{|u|_{\max }}, \frac{\Delta z}{|w|_{\max }}\right),
$$

where $|u|_{\max }$ and $|w|_{\max }$ are, respectively, the maximum horizontal and vertical flow speed within the high resolution domain at the previous timestep.

The background density of clear water $\rho_{w}$ is taken as horizontally uniform with the following depth dependance

$$
\rho_{w}(z)=\rho_{1}+\frac{\Delta \rho_{w}}{2}\left[1+\tanh \left(\frac{z-h_{1}}{\delta}\right)\right],
$$

where $\rho_{1}$ is the density of clear water at the sea surface, $\Delta \rho_{w}$ is the density difference between surface and bottom, $h_{1}$ is the surface layer thickness and $\delta$ is the pycnocline thickness. In the numerical experiments presented here $\rho_{1}$ and $\delta$ are fixed while $\Delta \rho_{w}$ and $h_{1}$ vary between experiments (see Tables 1 and 2 for details).

Table 2 further lists the mechanical energy $E_{i}$ of each initial wave as well as a series of non-dimensional parameters relevant to shoaling waves. The first, the Iribarren number, compares the slope of the boundary to the wave steepness and is defined as (Boegman et al., 2005)

$$
\xi=\frac{s}{(a / L)^{1 / 2}},
$$

where $a$ is the wave maximum displacement, or wave amplitude, and $L$ the characteristic wave horizontal lengthscale defined as the area displaced above the pycnocline divided by the wave amplitude (e.g. see Michallet and Ivey, 1999) (see Figure 2 for variable definitions). The second is the nonlinearity parameter

$$
\alpha=a / h_{1}
$$

that compares the wave amplitude to the surface layer thickness. Finally, the third is the ratio of the wave horizontal length scale to the length of the internal swash zone $L_{s} \equiv h_{1} / s$ i.e.

$$
\lambda=\frac{L}{L_{s}} .
$$

Similar horizontal length ratios were defined by Helfrich (1992) (he used $h_{2} / s$ for $L_{s}$ ) and Michallet and Ivey (1999) 
(they used $H_{\max } / s$ for $L_{s}$ ) and identified as fundamental parameters for processes associated with shoaling internal solitary waves. As will be shown below, we found that $\lambda$ as defined here better collapse the sediment data than the other two definitions.

The problem being already quite complex just with the physical parameters we have made the choice in this first study to fix all sediment parameters. The floc density $\rho_{s}$ and the erosion rate $F_{0}$ were taken from Wang et al. (2005). As for the critical shear stress $\tau_{c}$, we chose a value 5 times higher than used by Wang et al. (2005) that we considered more representative of the critical shear stress for resuspension of freshly deposited muddy bed.

\section{Results}

\subsection{Details of a single event}

Figure 2 shows the background density field and initial condition used to generate a rightward-propagating wave characterized with Iribarren number $\xi=0.13$ and normalized amplitude $\alpha=0.84$ (see run \#2 in Table 2). This situation, characterized with a wave-slope parameter $S_{w}=a / L=0.15$ and bottom slope $s=0.05$, falls within the collapsing breaker regime according to the classification of Aghsaee et al. (2010) (see their Figure 6). The wave is long relative to the total depth (i.e. $2 L \sim H_{\max }$, Table 2). One effect of this is that the waveinduced currents affect the entire water column. The deep flat bottom section of the environment is therefore also subject to wave-induced bottom shear stress that can potentially resuspend sediment there. All simulations presented here are for long internal solitary waves of this sort. The situation would be different if this wave were to propagate in relatively deep water (say if $2 L<0.1 H_{\max }$ ) in which case the deep flat bottom section would be mostly unaffected by the passage of such a wave. The case of short waves, relative to the total depth, is not considered in this study.

To put the results into an oceanographic context, the velocity field for this wave (Figure 2) is comparable to field situations reported in the St. Lawrence Estuary (e.g. Fig. 5 in Bourgault et al., 2007). The minimum and maximum horizontal waveinduced current are, respectively, $\min (u)=-0.2 \mathrm{~m} \mathrm{~s}^{-1}$ in the bottom layer and $\max (u)=0.4 \mathrm{~m} \mathrm{~s}^{-1}$ in the surface layer.

In the bottom cell, the maximum horizontal velocity is $\max \left(u_{b}\right)=-0.17 \mathrm{~m} \mathrm{~s}^{-1}$ which induces a maximum shear stress $\max \left(\left|\tau_{b}\right|\right)=2.5 \mathrm{~Pa}$. The bottom stress averaged over the wave horizontal length scale is $\bar{\tau}_{b}=0.8 \mathrm{~Pa}$. While this shear stress exceeds the prescribed critical shear stress for resuspension $\left(\tau_{c}=0.1 \mathrm{~Pa}\right)$, it causes little sediment resuspension as the wave propagates over the flat bottom section, with concentrations only reaching $0.02 \mathrm{~kg} \mathrm{~m}^{-1}$ (not shown). There are two main reasons for this. Firstly, the stress is applied only during the short duration of the wave passage ( $\sim 2 L / c \sim 3 \mathrm{~min})$. Secondly, while the vertical velocity is large near the pycnocline on both sides of the wave trough $\left(\max (|w|)=8.0 \times 10^{-2} \mathrm{~m} \mathrm{~s}^{-1}\right)$, it is two orders of magnitude smaller in the bottom cell with $\left|w_{b}\right|=2.8 \times 10^{-4} \mathrm{~m} \mathrm{~s}^{-1}$. Consequently, the little amount of resuspended sediment stays essentially within the thin $(\sim 1-\mathrm{m})$ wave-induced bottom boundary layer. In other words, because the wave is not turbulent, there is no efficient mechanism to propel resuspended sediment outside the wave-induced bottom nepheloid layer.

The situation is quite different as the wave interacts with the slope. As the wave shoals, the bottom-induced current roughly doubles when approaching the breaking point with the consequence of quadrupling both the bottom shear stress and sediment flux by virtue of Equations 6 and 10 (Figure 3, $t=21.0 \mathrm{~min}$ ). The wave then becomes distorted and breaks, with the production of density overturns as well as the creation of a series of up-slope propagating boluses charged with sediment. During this time, the near-bottom vertical velocity increases to large values reaching $w \sim 10^{-2} \mathrm{~m} \mathrm{~s}^{-1}$ (presented in more details below). This shoaling event is comparable to that of the collapsing breaker example presented in Aghsaee et al. (2010) (their Figures 7 and 12).

The combination of high bottom shear stress during shoaling and large near-bottom vertical velocity work together to create a thick $(\sim 10 \mathrm{~m})$ and sediment-rich bottom nepheloid layer (Figure 3, $t=38.5 \mathrm{~min}$ ), much richer and thicker than the thin $(\sim 1 \mathrm{~m})$ bottom nepheloid layer that was created during the propagation of the wave over the flat bottom section of the domain.

As time evolves (Figure 3, $t \geq 47.3 \mathrm{~min}$ ) and as the wave and bolus energy dissipates, two offshore spreading intermediate nepheloid layers are formed: a thick one, approximately $5 \mathrm{~m}$ thick just below the pycnocline and a thinner one, approximately $2 \mathrm{~m}$ thick, just above the pycnocline. These intermediate nepheloid layers intrude approximately $200 \mathrm{~m}$ offshore before coming to a halt (around $t=74.8 \mathrm{~min}$ ). After a long time (Figure 3, $t \geq 74.8 \mathrm{~min}$ ), the sediment slowly settles and the two intermediate nepheloid layers diffuse together.

Figure 4 shows the impact of two consecutive waves identical to the previous wave just discussed. The process is qualitatively similar to the case with only one impacting wave. One noticeable difference is the larger concentration of sediment that has been resuspended and the longer offshore extent of the predominant intermediate nepheloid layer.

To better understand when and where sediment resuspension takes place, we examine two quantities. The first is a time series of the mass of sediment found within the water column at any instant, i.e.

$$
M(t)=\int_{-1000 \mathrm{~m}}^{1000 \mathrm{~m}} \int_{-\eta}^{H(x)} C(x, z, t) d z d x \quad\left[\mathrm{~kg} \mathrm{~m}^{-1}\right],
$$

and its time derivative $d M / d t$. The second quantity is the along-slope distribution of the time-integrated bed erosion rate, i.e.

$$
\mathcal{F}_{b}(x)=\int_{0}^{6000 \mathrm{~s}} F_{b}(x, t) d t \quad\left[\mathrm{~kg} \mathrm{~m}^{-2}\right],
$$

where $F_{b}$ is as defined in Equation 10 for the situation where the bottom shear stress $\left|\tau_{b}\right|$ exceeds the critical shear stress $\tau_{c}$. These quantities are presented in Figures 5 and 6 for the situations of one and two impinging waves (runs \#2 and \#5) as well 
as for the sensitivity run with the grid resolution twice as high (Table 1).

The time series of the total resuspended mass $M(t)$ shows a remarkably smooth increase over time despite the presence of complex flow structures illustrated in Figures 3 and 4. Over the time simulated here $(\sim 100 \mathrm{~min})$, there is very little redeposition as seen by the plateau that $M(t)$ reaches after about $60 \mathrm{~min}$. This is because at the prescribed settling velocity $w_{s}=1 \times 10^{-4} \mathrm{~m} \mathrm{~s}^{-1}$, the settling time scale in this $\sim 10 \mathrm{~m}$ deep environment is of order 1 day, i.e. much longer than the simulated period. Redeposition processes are therefore omitted in the following analysis and discussion and are left for longer timescale studies. The spatial distribution of $\mathcal{F}_{b}$ shows that bed erosion takes place over the entire slope with a maximum reached at approximately $x=0.5 \mathrm{~km}$ for these runs (Figure 6).

Together, Figures 5 and 6 indicate that most of the resuspension for run \# 2 takes place somewhere in the following time and spatial frames: [25 min, $40 \mathrm{~min}$ ] and [0.50 km, $0.64 \mathrm{~km}$ ]. To help visualize and understand how sediment is being resuspended we present in Figures 7 and 8 details of the flow, density, sediment and vorticity fields, as well as the bottom sediment flux within these time and spatial frames.

Significant resuspension occurs with the formation of the first bolus (Figure 7, $t=22.3 \mathrm{~min}$ and $t=24.3 \mathrm{~min}$ ) which is also coincident with the formation of a large anticlockwise vortex formed just behind the shoaling wave (Figure 8 $t=24.3 \mathrm{~min}$ ). Note that the vorticity pattern seen here is comparable to the one seen in Figure 4 in Aghsaee et al. (2012). This suggests that this coarse-resolution model reasonably captures the inherent physics of shoaling waves for this situation. Two conditions are met at that location and time which favours propelling sediment far above the bottom boundary layer: the bottom flow and bottom stress are large, which induces sediment mobilization, and the near bottom vertical velocity is large which acts to lift the suspended sediment far up into the water column. By $t=26 \mathrm{~min}$, the first bolus is almost fully formed and is charged with sediment.

During the generation of this first bolus, the pycnocline remained stable without overturns, at least not at the scale resolved by this model configuration. Instabilities and density overturns appear behind the first bolus later on $(t=29.8 \mathrm{~min})$. Those instabilities contribute to mixing and to the creation of intermediate nepheloid layers found later just above and below the pycnocline.

To see how the above-pycnocline nepheloid layer is generated it is illuminating to follow the sediment pathway starting from the fully formed bolus centered around $x=705 \mathrm{~m}$ at $t=33.5 \mathrm{~min}$ (Figure 7, note the change in scale of the bottom sediment flux compared to previous panels). The bolusinduced bottom current is large and oriented upslope. This scrubs the bottom and concentrates sediment near the front face of the bolus where horizontal currents converge and the vertical velocity is large. Sediment is then carried upward and follows isopycnals until the point where the pycnocline becomes unstable and where sediment is left mixed within the water column, just above the pycnocline. By $t=37.3 \mathrm{~min}$, there are well developed nepheloid layers found just above and below the pycnocline. The lower nepheloid layer is principally formed during the initial wave breaking while the uppermost layer is formed by the boluses.

Figure 7 , at $t=37.3 \mathrm{~min}$, also shows that the while the boluses contain elevated sediment concentrations, the concentration in the very center is lower than the outer edge. This may appear somewhat surprising given that these boluses have trapped cores (Lamb, 2003), as evidenced by regions of closed streamlines in a frame of reference moving with the phase speed (not shown) and that the phase speed is less than the maximum horizontal velocity within the core (i.e. a Froude number of about 1.2). The fact that the sediment concentration within the center of the trapped cores is lower than around the edge may be surprising because it contrasts with the high optical backscatter observations that Klymak and Moum (2003) collected within the core of a similar bolus (or wave of elevation) observed on the Oregon continental shelf. The lower sediment concentration found here within the center of the simulated boluses suggests that at the time of formation, the fluid trapped within the innermost closed streamlines contained a lower amount of sediment (see for example the second bolus being formed on Figure 7, at $t=29.8 \mathrm{~min}$ ). It will be shown below that this result is consistent with field measurements of boluses observed in the St. Lawrence Estuary where the core may be characterized with lower acoustic backscatter (Figure 13).

\subsection{Sensitivity tests}

Figure 5 and 6 also show the sensitivity of the results for run \#2 to doubling both the horizontal and vertical resolution while also roughly doubling the time step. This sensitivity test indicates that doubling the spatial and temporal resolution leads to approximately $30 \%$ less sediment being resuspended (Figure 5). However, the timing, location and timescale of the resuspension event are comparable between the two simulations. Figure 9 compares the sediment distribution for the normal grid resolution and the higher resolution grid towards the end of the simulation, after most activities have ceased in the slope region. While the sediment concentration is lower by approximately $30 \%$ in the high resolution simulation, the general sediment patterns and the nepheloid layers are qualitatively similar, at least similar enough for the purpose of this research.

To test the sensitivity to the subgrid-scale Smagorinsky parameterization, a simulation with the standard resolution grid was carried out by letting $C_{s}=0$ in Equation 5. The results are virtually identical to the case with $C_{s}=0.1$ (not shown). This indicates that, not so surprisingly, numerical diffusion is dominant. The sensitivity test for grid resolution presented just above in fact also implicitly tested the impact of the numerics which depend on grid size.

We conclude from these sensitivity tests that the quantitative predictabilities of this model may not be accurate but that the inferred flow and sediment patterns may be sufficiently trusted to invite comparison with field observations and to frame hypotheses. 


\subsection{Parameterizations}

While the previous sections examined the details of single events, we now provide more general relationships found between some simulated characteristics of the resuspended sediment and the control parameters. These relationships may provide useful parameterizations for studying and interpreting wave-induced sediment processes.

The first relationship found links the maximum offshore extent $L_{n}$ of intermediate nepheloid layers to the incoming wave energy $E_{i}$. Here $L_{n}$ was determined by calculating the maximum offshore position where the depth-averaged sediment concentration, excluding the bottom boundary layer, exceeds $10^{-4} \mathrm{~kg} \mathrm{~m}^{-3}$. The calculation is not very sensitive to this criterion. For example, using a threshold 10 times smaller $\left(10^{-5} \mathrm{~kg} \mathrm{~m}^{-3}\right)$ or larger $\left(10^{-3} \mathrm{~kg} \mathrm{~m}^{-3}\right)$ leads to a $5 \%$ difference is the average calculated length $L_{n}$. This distance is calculated relative to the interface-slope position (see $L_{n}$ on Figure 1). A statistically significant linear relationship, that holds for both one-wave and two-wave cases, was found between $L_{n} / L_{s}$ and $E_{i} / E_{0}$, where

$$
E_{0}=g \Delta \rho \delta^{2} L
$$

is proportional to the potential energy of the base stratification over a distance corresponding to the length of the waves (Figure 10). The regression suggests a power law with exponent close to $3 / 4$, i.e.

$$
L_{n}=0.39 L_{s}\left(\frac{E_{i}}{E_{0}}\right)^{0.70}
$$

(Figure 10). This relationship indicates that the excursion length of intermediate nepheloid layers $L_{n}$ is proportional to the length of the internal swash zone $L_{s}$, given everything else the same.

The second statistically significant relationship found links the maximum mass of suspended sediment $M_{\max }$ to the incoming wave energy $E_{i}$ weighted by the inverse of the normalized wavelength $\lambda$, a relationship that also holds for both one-wave and two-wave cases (Figure 11). This relationship suggests that $\lambda$ may be a fundamental parameter controlling wave-induced sediment resuspension. In other words, for a given incoming wave energy, the longer the internal swash zone $L_{s}$ is, relative to the length of the incoming waves $L$, the more susceptible the environment is to sediment resuspension. This can also be understood in terms of wave-slope reflectance. Longer slopes, relative to wave horizontal lengthscales, can absorb more wave energy, in turn available for sediment resuspension, than short slopes (Helfrich, 1992; Michallet and Ivey, 1999). Although more recent studies have favored using the Iribarren number to express wave-slope reflectance (Boegman et al., 2005; Bourgault and Kelley, 2007; Lamb and Nguyen, 2009; Aghsaee et al., 2010), the results here for sediment resuspension show somewhat better agreement when examined in terms of the simpler length scale ratio $\lambda\left(R^{2}=0.93\right.$ for $M_{\max }=f\left(E_{i} / \lambda\right)$ compared to $R^{2}=0.86$ for $\left.M_{\max }=f\left(E_{i} / \xi\right)\right)$.

Finally, the third statistically significant relationship found links the distance from the shoreline of the point of maximum bed erosion $L_{b}-x_{e}\left(L_{b}\right.$ is the total length of the sloping boundary, see Figure 2 ) to the horizontal position determined by $\left(a+h_{1}\right) / s$, i.e. the projection of the vertical position of the wave trough $\left(a+h_{1}\right)$ onto the slope $s$ (Figure 12). This relationship of slope $=1.13 \pm 0.04(95 \%$ c.i. $)\left(R^{2}=0.99 p<0.01\right)$ indicates that the maximum bed erosion occurs a little offshore from the intersection of the wave trough projection. Note that these three relationships do not show any dependance on the type of wave shoaling regimes.

\section{Discussion}

\subsection{Qualitative comparisons with field observations}

Results presented here provide plausible answers to questions raised on Figure 1 regarding acoustic patterns. The observed mid-depth, tonguelike acoustic structure seen on that figure is likely an intermediate nepheloid layer induced by a shoaling wavetrain. Also, the high acoustic backscatter associated with boluses likely reflects, at least partly, higher than background sediment concentration. Theses inferences are based on the striking visual similarities between the field observations (Figure 1) and model results (Figure 3, Figure 4).

Another comparison is worth presenting. Figure 13 shows a qualitative comparison between a bolus observed in the St. Lawrence Estuary by Richards et al. (2013) and one simulated here (extracted from run \# 2). Assuming that the acoustic backscatter is proportional to sediment concentration (Holdaway et al., 1999), the visual comparison is, here again, striking. The model results provide a plausible explanation for the sediment pattern seen within and around the observed bolus, highlighting the ability of the bolus the erode the bottom substrate and to lift sediment 5-10 meters above the bottom.

The model results further provide an explanation as to why some boluses are characterized with a central core of lower acoustic backscatter than at their perimeters. This is something we have observed on many occasions in the field (see for example the second bolus presented in the top panel of Figure 1).

\subsection{Implications for sedimentology}

As suggested here, sediment resuspension and the development of nepheloid layers caused by shoaling and breaking internal solitary waves in idealized two-layer coastal systems can be an effective transport mechanism; these nepheloid layers intrude offshore a distance $L_{n}$ (Figure 10) and subsequently settle down thus contributing to net downslope sediment flux. However, the depositional length (or area) is likely greater than $L_{n}$ in natural coastal environments given the slow settling velocity compared to fast turbulent eddies of other origins and large horizontal advection from tidal and residual currents. In either case, this mechanism by which intermediate nepheloid layers are produced by shoaling waves may be important for muddy sediment dispersal and net-downslope transport along continental shelves, especially given the widespread occurrence of such waves in coastal environments.

Such dispersal and transport mechanisms associated with shoaling internal solitary waves, or similar processes associated with internal waves in a more general sense, may offer an 
alternative explanation to the presence of some erosion surfaces still not well understood. For example, Schieber and Yawar (2009) suggested that a proportion of mud in the Eau Claire Formation (Upper Cambrian Indiana, USA) did not simply accumulate from material that settled out from suspension. The sedimentary structures rather suggest distinct depositional events that were accompanied by initial erosion. They interpreted the cross-laminated mudstones, together with the presence of hummocky cross-stratification beds within this succession, as the result of storms of lesser magnitude that were not capable of transporting large quantities of sand, or alternatively may be the distal tails of storm-induced currents that originated at a greater distance. But an alternative view that can explain the presence of erosion surfaces, as well as the occurrence of hummocky cross-stratification beds in the sandy intervals, is the impact of internal waves breaking on the seafloor and their induced up- and downslope currents, as well as their oscillatory flow (e.g. Morsilli and Pomar, 2012; Pomar et al., 2012). Shoaling internal solitary waves of the type examined in this study may well contribute to shaping such sedimentary structures.

\section{Conclusion}

The results presented here, based on idealized numerical simulations, suggest that shoaling internal solitary waves may erode, resuspend and transport mud-like sediments, first towards shore by boluses, and subsequently offshore through the generation of intermediate and bottom nepheloid layers. Given the widespread occurrences of these waves in coastal environments, this further suggests that shoaling internal solitary waves may be an important mechanism of muddy sediments dispersal along continental shelves as well as providing significant net-downslope sediment transport. However, the theoretical predictions presented here should be taken cautiously given the simplicity of our approach compared to the complexity of processes involved, noting that internal solitary waves and cohesive sedimentation are both outstanding problems by themselves in Oceanography. Nevertheless, the qualitative similarities between our idealized model and natural field observations is encouraging and suggests that further research is warranted. Many theoretical questions remain to be addressed. Equally importantly, it would be helpful to carry out new field experiments designed to obtain direct measurements of sediment resuspension and transport caused by shoaling internal solitary waves, perhaps guided by the present findings.

\section{Acknowledgements}

We would like to thank the anonymous reviewers as well as the Editors for their constructive and valuable comments to help improve the manuscript as well as Alex Hay for his partnership and continuing discussions about wave-induced sediment processes. This research was funded by the Natural Sciences and Engineering Research Council of Canada (D. Bourgault) and by the Spanish Research Project CGL2009-13254
(M. Morsilli). This research is a contribution to the scientific program of Québec-Océan. 


\section{References}

Aghsaee, P., Boegman, L., Diamessis, P. J., Lamb, K. G., 2012. Boundarylayer-separation-driven vortex shedding beneath internal solitary waves of depression. J. Fluid Mech. 690 (1), 321-344.

Aghsaee, P., Boegman, L., Lamb, K. G., 2010. Breaking of shoaling internal solitary waves. J. Fluid Mech. 659, 289-317.

Bádenas, B., Pomar, L., Aurell, M., Morsilli, M., 2012. A facies model for internalites (internal wave deposits) on a gently sloping carbonate ramp (Upper Jurassic, Ricla, NE Spain). Sediment. Geol. 271-272, 44-57.

Boegman, L., Ivey, G. N., 2009. Flow separation and resuspension beneath shoaling nonlinear internal waves. J. Geophys. Res. 114 (C02018).

Boegman, L., Ivey, G. N., Imberger, J., 2005. The degeneration of internal waves in lakes with sloping topography. Limnol. Oceanogr. 50, 1620-1637.

Bogucki, D., Dickey, T., Redekopp, L. G., 1997. Sediment resuspension and mixing by resonantly generated internal solitary waves. J. Phys. Oceanogr. 27, 1181-1196.

Bogucki, D., Redekopp, L. G., Barth, J., 2005. Internal solitary waves in the Coastal Mixing and Optics 1996 experiment: Multimodal structure and resuspension. J. Geophys. Res. 110 (C02024).

Bogucki, D. J., Redekopp, L. G., 1999. A mechanism for sediment resuspension by internal solitary waves. Geophys. Res. Lett. 26 (9), 1317-1320.

Bogucki, D. J., Redekopp, L. G., 2008. Climate of long internal waves and resuspension on the coastal shelf. Oceanologia 50 (1), 5-21.

Bourgault, D., Blokhina, M., Mirshak, R., Kelley, D. E., 2007. Evolution of a shoaling internal solitary wavetrain. Geophys. Res. Lett. 34, L03601, doi:10.1029/2006GL028462.

Bourgault, D., Kelley, D. E., 2004. A laterally averaged nonhydrostatic ocean model. J. Atmos. Oceanic Technol. 21 (12), 1910-1924.

Bourgault, D., Kelley, D. E., 2007. On the reflectance of uniform slopes for normally incident interfacial solitary waves. J. Phys. Oceanogr. 37 (5), 1156-1162.

Bourgault, D., Kelley, D. E., Galbraith, P. S., 2005. Interfacial solitary wave run-up in the St. Lawrence Estuary. J. Mar. Res. 63 (6), 1001-1015.

Bourgault, D., Kelley, D. E., Galbraith, P. S., 2008. Turbulence and boluses on an internal beach. J. Mar. Res. 66 (5), 563-588.

Carr, M., Davies, P. A., Shivaram, P., 2008. Experimental evidence of internal solitary wave-induced global instability in shallow water benthic boundary layers. Phys. Fluids 20, 066603.

Carter, G. S., Gregg, M. C., Lien, R.-C., 2005. Internal waves, solitary-like waves, and mixing on the Monterey Bay shelf. Cont. Shelf Res. 25, 14991520 .

Diamessis, P. J., Redekopp, L. G., 2006. Numerical investigation of solitary internal wave-induced global instability in shallow water benthic boundary layers. J. Phys. Oceanogr. 36, 784-812

Farmer, D. M., Armi, L., 1999. The generation and trapping of internal solitary waves over topography. Science 283 (5398), 188-190.

Fettweis, M., 2008. Uncertainty of excess density and settling velocity of mud flocs derived from in situ measurements. Estuar. Coast. Shelf Sci. 78, 426436

Grant, W. D., Madsen, O. S., 1986. The continental-shelf bottom boundary layer. Annu. Rev. Fluid Mech. 18 (1), 265-305.

Helfrich, K. R., 1992. Internal solitary wave breaking and run-up on a uniform slope. J. Fluid Mech. 243, 133-154.

Helfrich, K. R., Melville, W. K., 2006. Long nonlinear internal waves. Annu. Rev. Fluid Mech. 38, 395-425.

Holdaway, G., Thorne, P., Flatt, D., Jones, S., Prandle, D., 1999. Comparison between ADCP and transmissometer measurements of suspended sediment concentration. Cont. Shelf Res. 19 (3), 421.

Hosegood, P., Bonnin, J., van Haren, H., 2004. Solibore-induced sediment resuspension in the faeroe-shetland channel. Geophys. Res. Lett. 31 (L09301).

Hosegood, P., van Haren, H., 2004. Near-bed solibores over the continental slope in the Faeroe-Shetland Channel. Deep-Sea Res. II 51, 2943-2971.

Johnson, D. R., Weidemann, A., Pegau, W. S., 2001. Internal tidal bores and bottom nepheloid layers. Cont. Shelf Res. 21, 1473-1484.

Klymak, J. M., Moum, J. N., 2003. Internal solitary waves of elevation advancing on a shoaling shelf. Geophys. Res. Lett. 30 (20), 2045, doi:10.1029/2003GL017706.

Lamb, K. G., 2002. A numerical investigation of solitary internal waves with trapped cores formed via shoaling. J. Fluid Mech. 451, 109-144 DOI: 10.1017/S002211200100636X.
Lamb, K. G., 2003. Shoaling solitary internal waves: on a criterion for the formation of waves with trapped cores. J. Fluid Mech. 478, 81-100.

Lamb, K. G., Nguyen, V. T., 2009. Calculating energy flux in internal solitary waves with an application to reflectance. J. Phys. Oceanogr. 39, 559-580.

Michallet, H., Ivey, G. N., 1999. Experiments on mixing due to internal solitary waves breaking on uniform slopes. J. Geophys. Res. 104 (C6), 1346713477.

Morsilli, M., Pomar, L., 2012. Internal waves vs. surface storm waves: a review on the origin of hummocky cross-stratification. Terra Nova 24, 273 282.

Pan, X., Wong, G. T. F., F.-K., Ho, T.-Y., 2012. Enhancement of biological productivity by internal waves: observations in the summertime in the northern south china sea. Journal of Oceanography 68 (3), 427-437.

Pomar, L., Morsilli, M., Hallock, P., Bádenas, B., 2012. Internal waves, an under-explored source of turbulence events in the sedimentary record. Earth-Sci. Rev. 111, 56-81.

Pomar, L., Morsilli, M., Hallock, P., Bádenas, B., Bourgault, D., 2013. Reply to Shanmugam, G., comment on "internal waves, an underexplored source of turbulence events in the sedimentary record" by Pomar et al. [EarthScience Reviews, 111 (2012), 5681], Earth Science Reviews (2012). EarthSci. Rev. 116, 206-210.

Quaresma, L. S., Vitorino, J., Oliveira, A., da Silva, J., 2007. Evidence of sediment resuspension by nonlinear internal waves on the western portuguese mid-shelf. Mar. Geol. 246, 123-143.

Richards, C. G., Bourgault, D., Galbraith, P. S., Hay, A., Kelley, D. E., 2013. Measurements of shoaling internal waves and turbulence in an estuary. J. Geophys. Res. 118, 1-14.

Sandstrom, H., Elliott, J. A., 1984. Internal tide and solitons on the Scotian Shelf: A nutrient pump at work. J. Geophys. Res. 89 (C4), 6415-6426.

Schieber, J., Yawar, Z., 2009. A new twist on mud deposition - mud ripples in experiment and rock record. The Sedimentary Record 7 (2), 4-8.

Smagorinsky, J., 1963. General circulation experiments with primitive equations. I. The basic experiment. Mon. Weather Rev. 91 (3), 99-164.

Smyth, C., Hay, A. E., 2002. Wave friction factors in nearshore sands. J. Phys. Oceanogr. 32 (12), 3490-3498.

Stastna, M., Lamb, K. G., 2002. Vortex shedding and sediment resuspension associated with the interaction of an internal solitary wave and the bottom boundary layer. Geophys. Res. Lett. 29 (11).

Stastna, M., Lamb, K. G., 2008. Sediment resuspension mechanisms associated with internal waves in coastal waters. J. Geophys. Res. 113 (C10016).

Turkington, B., Eydeland, A., Wang, S., 1991. A computational method for solitary internal waves in a continuously stratified fluid. Stud. App. Math. 85, 93-127.

Venayagamoorthy, S. K., Fringer, O. B., 2007. On the formation and propagation of nonlinear internal boluses across a shelf break. J. Fluid Mech. 577, 137.

Venayagamoorthy, S. K., Fringer, O. B., 2012. Examining breaking internal waves on a shelf slope using numerical simulations. Oceanography 25 , $132-139$.

Vitousek, S., Fringer, O. B., 2011. Physical vs. numerical dispersion in nonhydrostatic ocean modeling. Ocean Model. 40 (1), 72-86.

Wang, X. H., 2002. Tide-induced sediment resuspension and the bottom boundary layer in an idealized estuary with a muddy bed. J. Phys. Oceanogr. 32, 3113-3131.

Wang, X. H., Byun, D. S., Wang, X. L., Cho, Y. K., 2005. Modelling tidal currents in a sediment stratified idealized estuary. Cont. Shelf Res. 25, 655665.

Winterwerp, J., Van Kesteren, W., 2004. Introduction to the physics of cohesive sediment in the marine environment. Vol. 56. Elsevier Science Limited. 
Table 1: Fixed parameters used in the hydrodynamic/sediment model. Numbers in parentheses are values of those parameters that were subject to a sensitivity analysis. The sensitivity of the results to the other parameters has not been examined in this study.

\begin{tabular}{lr}
\hline Parameter & Value \\
\hline Maximun depth $H_{\max }$ & $50 \mathrm{~m}$ \\
Horizontal grid size $\Delta x$ & $1(0.5) \mathrm{m}$ \\
Vertical grid size $\Delta z$ & $0.25(0.125) \mathrm{m}$ \\
Reference water density $\rho_{0}$ & $1024 \mathrm{~kg} \mathrm{~m}^{-3}$ \\
Smagorinsky coef. $C_{s}$ & $0.1(0)$ \\
Surface background density $\rho_{1}$ & $1019.5 \mathrm{~kg} \mathrm{~m}^{-3}$ \\
Bottom roughness length $z_{0}$ & $1.0 \times 10^{-3} \mathrm{~m}$ \\
Pycnocline thickness $\delta$ & $3.5 \mathrm{~m}$ \\
Sediment floc density $\rho_{s}$ & $1100 \mathrm{~kg} \mathrm{~m}^{-3}$ \\
Settling velocity $w_{s}$ & $1.0 \times 10^{-4} \mathrm{~m} \mathrm{~s}^{-1}$ \\
Erosion coefficient $F_{0}$ & $1.0 \times 10^{-4} \mathrm{~kg} \mathrm{~m}^{-2} \mathrm{~s}^{-1}$ \\
Critical shear stress $\tau_{c}$ & $0.1 \mathrm{~Pa}$ \\
\hline
\end{tabular}




\begin{tabular}{|c|c|c|c|c|c|c|c|c|c|c|c|}
\hline $\begin{array}{l}\text { Run \# } \\
1 \text { ISW }\end{array}$ & $\begin{array}{l}\text { Run \# } \\
2 \text { ISW }\end{array}$ & $s$ & $\begin{array}{c}h_{1} \\
(\mathrm{~m})\end{array}$ & $\begin{array}{c}\Delta \rho_{w} \\
\left(\mathrm{~kg} \mathrm{~m}^{-3}\right)\end{array}$ & $\begin{array}{c}a \\
(\mathrm{~m})\end{array}$ & $\begin{array}{c}L \\
(\mathrm{~m})\end{array}$ & $\begin{array}{c}c \\
\left(\mathrm{~m} \mathrm{~s}^{-1}\right)\end{array}$ & $\begin{array}{c}E_{i} \\
\left(\mathrm{~J} \mathrm{~m}^{-1}\right) \\
\end{array}$ & $\xi$ & $\alpha$ & $\lambda$ \\
\hline 1 & 4 & 0.05 & 10 & 4.50 & 5.4 & 55.6 & 0.61 & $8.6 \times 10^{4}$ & $0.16_{+}$ & 0.54 & 0.28 \\
\hline 2 & 5 & 0.05 & 10 & 4.50 & 8.4 & 55.2 & 0.64 & $2.2 \times 10^{5}$ & $0.13_{+}$ & 0.84 & 0.28 \\
\hline 3 & 6 & 0.05 & 10 & 4.50 & 12.8 & 63.1 & 0.67 & $6.2 \times 10^{5}$ & $0.11_{+}$ & 1.28 & 0.32 \\
\hline$\overline{7}$ & $-\overline{10}$ & $0 . \overline{2}$ & $1 \overline{0}$ & $\overline{4} . \overline{5} 0^{-}$ & $\overline{5} . \overline{4}$ & $\overline{55.6}$ & $\overline{0} . \overline{6} 1^{-}$ & $\overline{8} . \overline{6} \times \overline{10} 0^{\overline{4}}$ & $\overline{0} . \overline{0} \overline{6}_{x}^{-}$ & $\overline{0} . \overline{5} 4$ & $\overline{0.1} \overline{1}$ \\
\hline 8 & 11 & 0.02 & 10 & 4.50 & 8.4 & 55.2 & 0.64 & $2.2 \times 10^{5}$ & $0.05_{x}$ & 0.84 & 0.11 \\
\hline 9 & 12 & 0.02 & 10 & 4.50 & 12.8 & 63.1 & 0.67 & $6.2 \times 10^{5}$ & $0.04_{+}$ & 1.28 & 0.13 \\
\hline$\overline{13}$ & $1 \overline{6}$ & 0.05 & $1 \overline{0}$ & $2 . \overline{25}$ & $\overline{7} . \overline{6}$ & $\overline{54.0}$ & $\overline{0} . \overline{4} 5$ & $\overline{8} . \overline{6} \overline{\times} \overline{10} 0^{4}$ & $\overline{0 .} \overline{1} 3_{+}^{-}$ & $\overline{0} . \overline{7} 6$ & $0 . \overline{2} \overline{7}$ \\
\hline 14 & 17 & 0.05 & 10 & 2.25 & 11.2 & 58.2 & 0.47 & $2.2 \times 10^{5}$ & $0.11_{+}$ & 1.12 & 0.29 \\
\hline 15 & 18 & 0.05 & 10 & 2.25 & 15.3 & 82.3 & 0.48 & $6.1 \times 10^{5}$ & $0.12_{+}$ & 1.53 & 0.41 \\
\hline $19^{-}$ & $\overline{2} \overline{2}$ & $\overline{0.0 \overline{2}}$ & $\overline{10}$ & $\overline{2} . \overline{25}$ & $\overline{7} . \overline{6}$ & $\overline{54.0}$ & $\overline{0} . \overline{4} 5$ & $\overline{8} . \overline{6} \overline{\times} \overline{10} 0^{\overline{4}}$ & $\overline{0} . \overline{0} 5_{x}^{-}$ & $\overline{0.76}$ & $\overline{0.1 \overline{1}}$ \\
\hline 20 & 23 & 0.02 & 10 & 2.25 & 11.2 & 58.2 & 0.47 & $2.2 \times 10^{5}$ & $0.05_{+}$ & 1.12 & 0.12 \\
\hline 21 & 24 & 0.02 & 10 & 2.25 & 15.3 & 82.3 & 0.48 & $6.1 \times 10^{5}$ & $0.05_{+}$ & 1.53 & 0.16 \\
\hline$\overline{25}$ & $2 \overline{8}$ & $0 . \overline{40}$ & $1 \overline{0}$ & $\overline{4} . \overline{5} 0^{-}$ & $\overline{5} . \overline{4}$ & 55.6 & $\overline{0} . \overline{6} 1$ & $\overline{8} . \overline{6} \times \overline{10} 0^{\overline{4}}$ & $\overline{1} . \overline{2} 8_{\circ}^{-}$ & $\overline{0} . \overline{5} 4$ & $2.2^{-}$ \\
\hline 26 & 29 & 0.40 & 10 & 4.50 & 8.4 & 55.2 & 0.64 & $2.2 \times 10^{5}$ & 1.02 。 & 0.85 & 2.2 \\
\hline 27 & 30 & 0.40 & 10 & 4.50 & 12.8 & 63.1 & 0.67 & $6.2 \times 10^{5}$ & 0.89 。 & 1.28 & 2.5 \\
\hline$\overline{3} 1^{-}$ & & $0 . \overline{05}$ & $2 \overline{0}$ & $-\overline{4} . \overline{5} 0^{-}$ & $\overline{3} . \overline{2}$ & $\overline{1} \overline{4} \bar{T}$ & $\overline{0} . \overline{6} 8^{-}$ & $\overline{8} . \overline{2} \overline{\times} \overline{10} 0^{4}$ & $\overline{0} . \overline{3} \overline{4}_{\times}$ & $\overline{0} . \overline{16}$ & $\overline{0.3} \overline{6}$ \\
\hline 32 & - & 0.05 & 20 & 4.50 & 4.8 & 160 & 0.68 & $2.1 \times 10^{5}$ & $0.29_{x}$ & 0.24 & 0.40 \\
\hline 33 & & 0.05 & 20 & 4.50 & 5.9 & 267 & 0.68 & $5.9 \times 10^{5}$ & $0.34_{x}$ & 0.30 & 0.67 \\
\hline$\overline{3} 7$ & - & $0 . \overline{0}$ & $2 \overline{0}$ & $\overline{4} . \overline{5} 0^{-}$ & $\overline{3} . \overline{2}$ & $\overline{1} \overline{44}$ & $\overline{0} . \overline{6} 8$ & $\overline{8} . \overline{2} \overline{\times} \overline{10} 0^{4}$ & $\overline{0} . \overline{13} \hat{x}$ & $\overline{0.16}$ & $0 . \overline{1} \overline{4}$ \\
\hline 38 & - & 0.02 & 20 & 4.50 & 4.8 & 160 & 0.68 & $2.1 \times 10^{5}$ & $0.12_{x}$ & 0.24 & 0.16 \\
\hline 39 & - & 0.02 & 20 & 4.50 & 5.9 & 267 & 0.68 & $5.9 \times 10^{5}$ & $0.13_{x}$ & 0.30 & 0.27 \\
\hline
\end{tabular}

Table 2: Run ID numbers and control parameters. $s$ is the bottom slope, $h_{1}$ the surface layer thickness, $\Delta \rho$ the density difference between the bottom and surface layers, $a$ the wave maximum displacement or, equivalently, the wave amplitude, $L$ the wave horizontal lengthscale or, equivalently, the wavelength, $c$ the phase speed, $E_{i}$ the total mechanical energy, $\xi$ the Iribarren number, $\alpha$ the amplitude relative to the top layer thickness $h_{1}$, and $\lambda$ the wavelength relative to the length of the swash zone $L_{s}$ (see Figure 2 for a definition sketch of these variables). The second column corresponds to runs with two identical incident waves. The incident energy $E_{i}$ for those runs needs to be multiplied by two. The indices that accompany the Iribarren number $\xi$ refer to the type of shoaling mechanism according to the classification of Aghsaee et al. (2010), where '+' refers to collapsing breaker, ' $x$ ' to fission and, 'o' to plunging. 


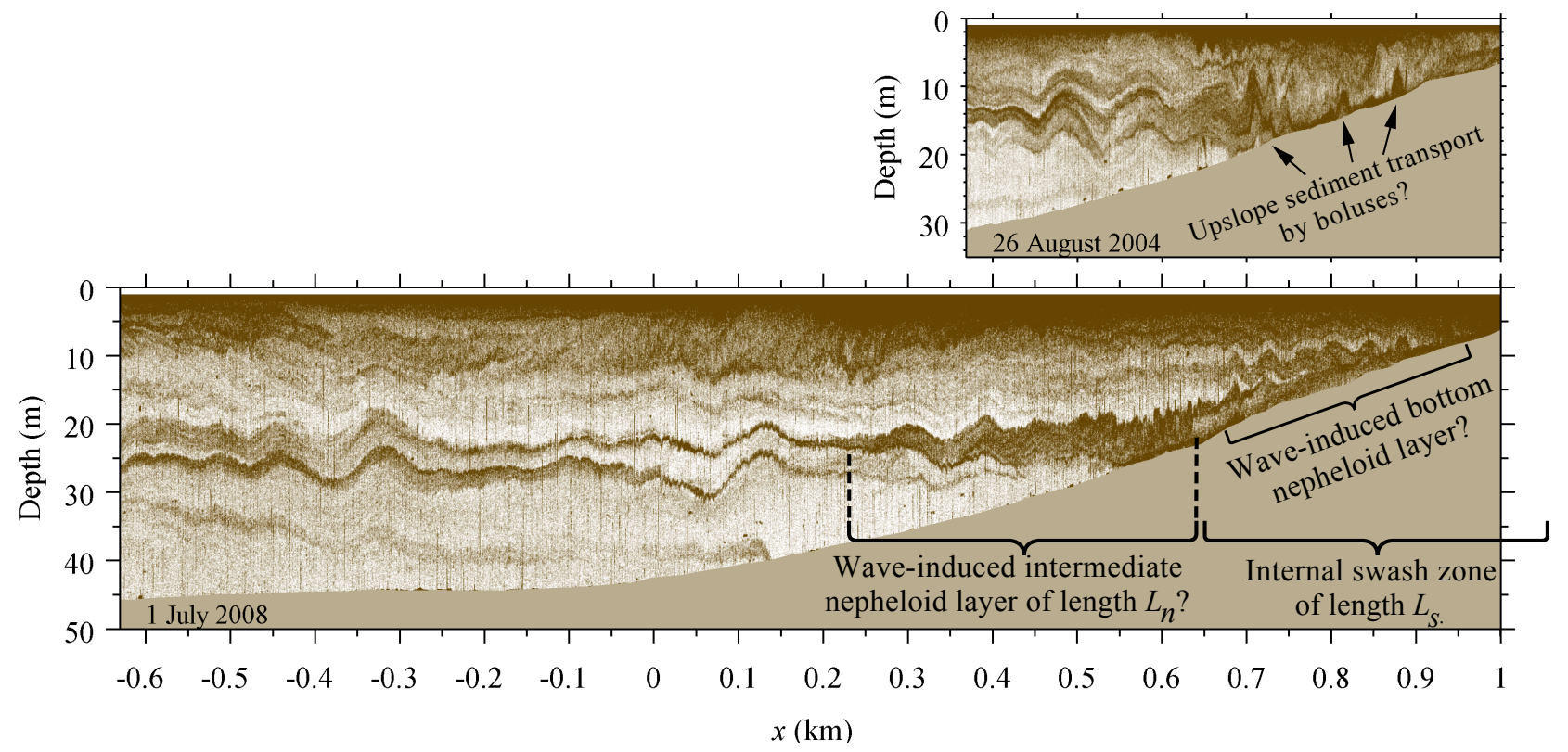

Figure 1: Sample echograms (120 kHz, arbitrary units) suggestive of sediment transport induced by shoaling internal solitary-like waves along the flank of Ileaux-Lièvres, an island in the St. Lawrence Estuary. The top echogram suggests upslope sediment transport by boluses produced during the shoaling of an internal solitary wavetrain (see Bourgault et al., 2007, for details about this particular event). The bottom echogram suggest the existence of both bottom and intermediate nepheloid layers remnant of a shoaling internal solitary wavetrain (see Richards et al., 2013, for details of the shoaling wave process prior to this). The length of the feature identified as a possible intermediate nepheloid layer is $L_{n} \approx 400 \mathrm{~m}$ and the length of the internal swash zone is here also $L_{s} \approx 400 \mathrm{~m}$ (see text and Figure 2 for more details about the definition of these lengths). 


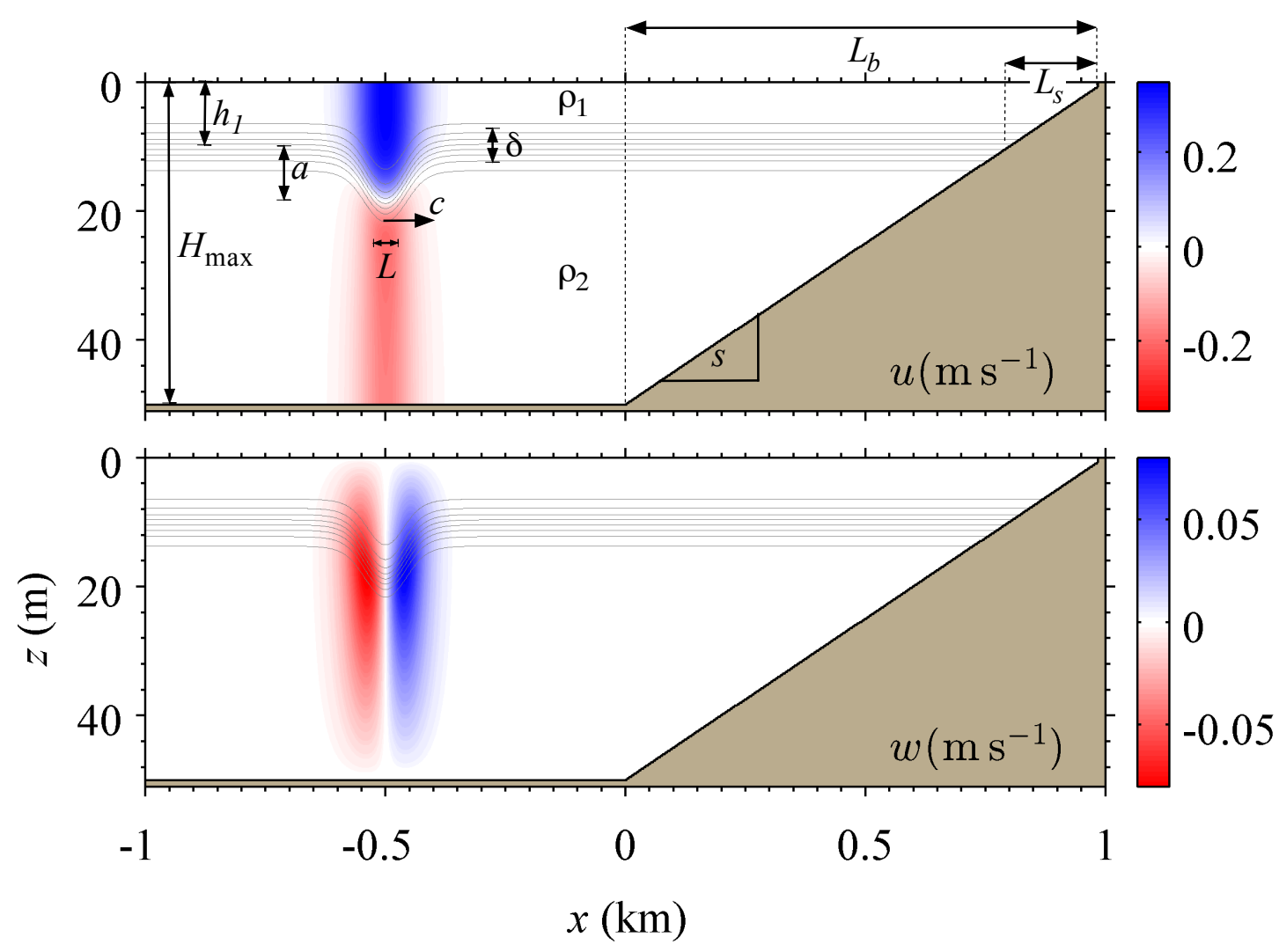

Figure 2: Parameters definition and example of a shoreward propagating internal solitary wave (run \#2, Table 1$)$ as initialized in the high resolution $(\Delta x=1 \mathrm{~m})$ domain geometry. The isolines are water density at $0.5 \mathrm{~kg} \mathrm{~m}^{-3}$ interval. The numerical domain extends another $9 \mathrm{~km}$ leftward (not shown) where the horizontal grid size steadily decreases to $\Delta x_{\max }=100 \mathrm{~m}$. 

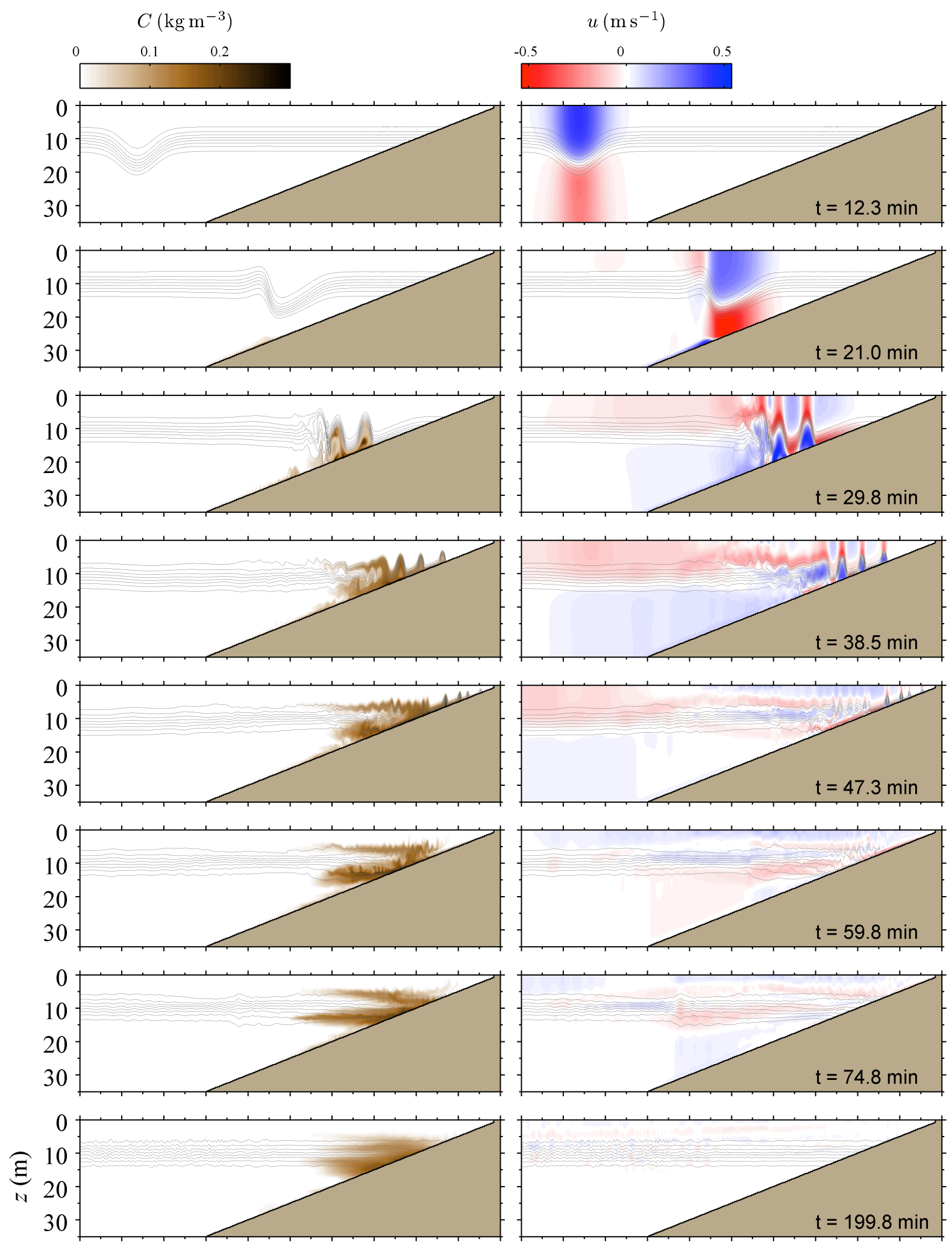

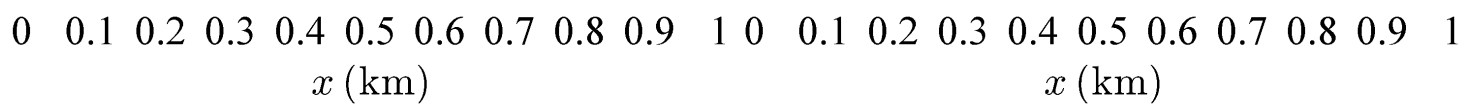

Figure 3: Model results of run \#2 (Table 2). (left) Sediment concentration $C\left(\mathrm{~kg} \mathrm{~m}^{-3}\right)$ and (right) horizontal velocity $u$ ( $\mathrm{m} \mathrm{s}^{-1}$ ). Isopycnals are also superimposed on each field as thin gray isolines $0.5 \mathrm{~kg} \mathrm{~m}^{-3}$ apart. 

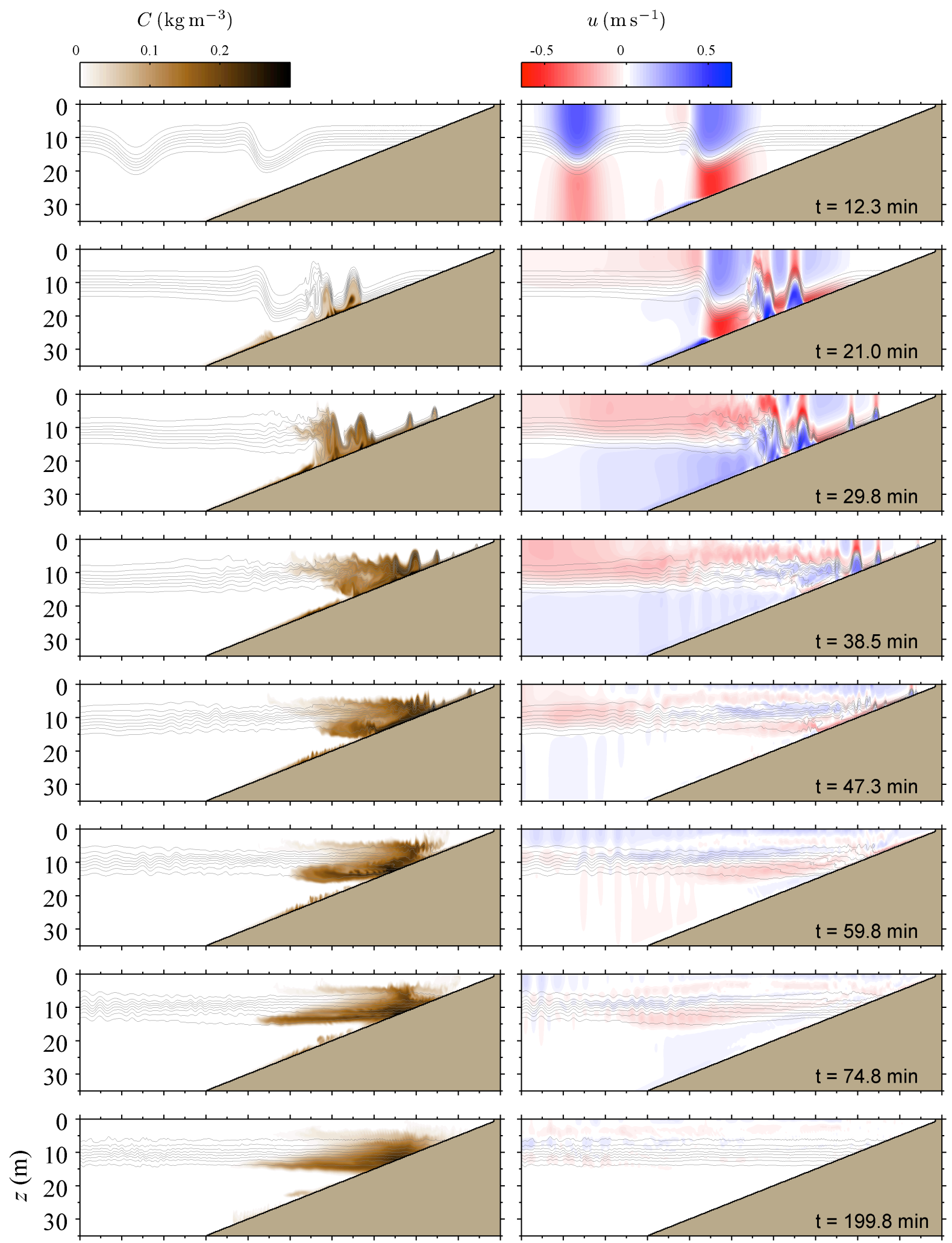
$\begin{array}{llllllllllllllllllllll}0 & 0.1 & 0.2 & 0.3 & 0.4 & 0.5 & 0.6 & 0.7 & 0.8 & 0.9 & 1 & 0 & 0.1 & 0.2 & 0.3 & 0.4 & 0.5 & 0.6 & 0.7 & 0.8 & 0.9 & 1\end{array}$ $x(\mathrm{~km})$ $x(\mathrm{~km})$




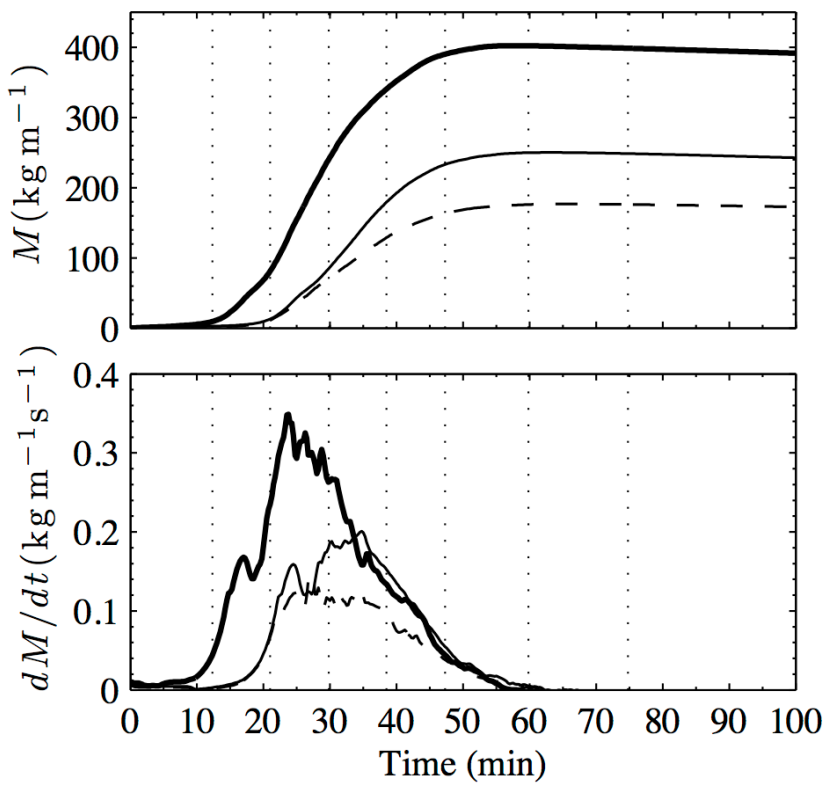

Figure 5: Time series of (top) the total mass of suspended sediment $M$ and (bottom) its time derivative $d M / d t$ for run \#2 (Figure 3 , thin solid line), run \#5 (Figure 4, thick solid line) and for the sensitivity run with twice the grid resolution (dashed line, same settings as run \#2). Vertical dotted lines are time steps illustrated in Figures 3 and 4. 


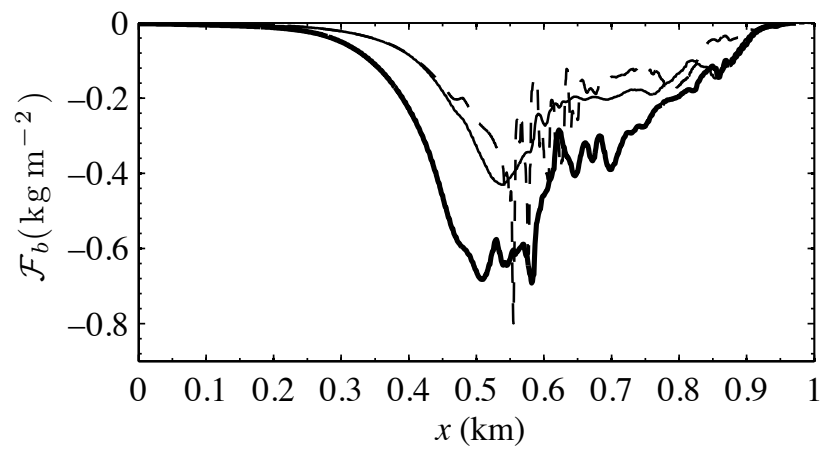

Figure 6: Spatial distribution of the time-integrated bed erosion $\mathcal{F}_{b}$ (Equation 19) for run \#2 (Figure 3, thin solid line), run \#5 (Figure 4, thick solid line) and for the sensitivity run with twice the grid resolution (dashed line, same settings than run \#2). 


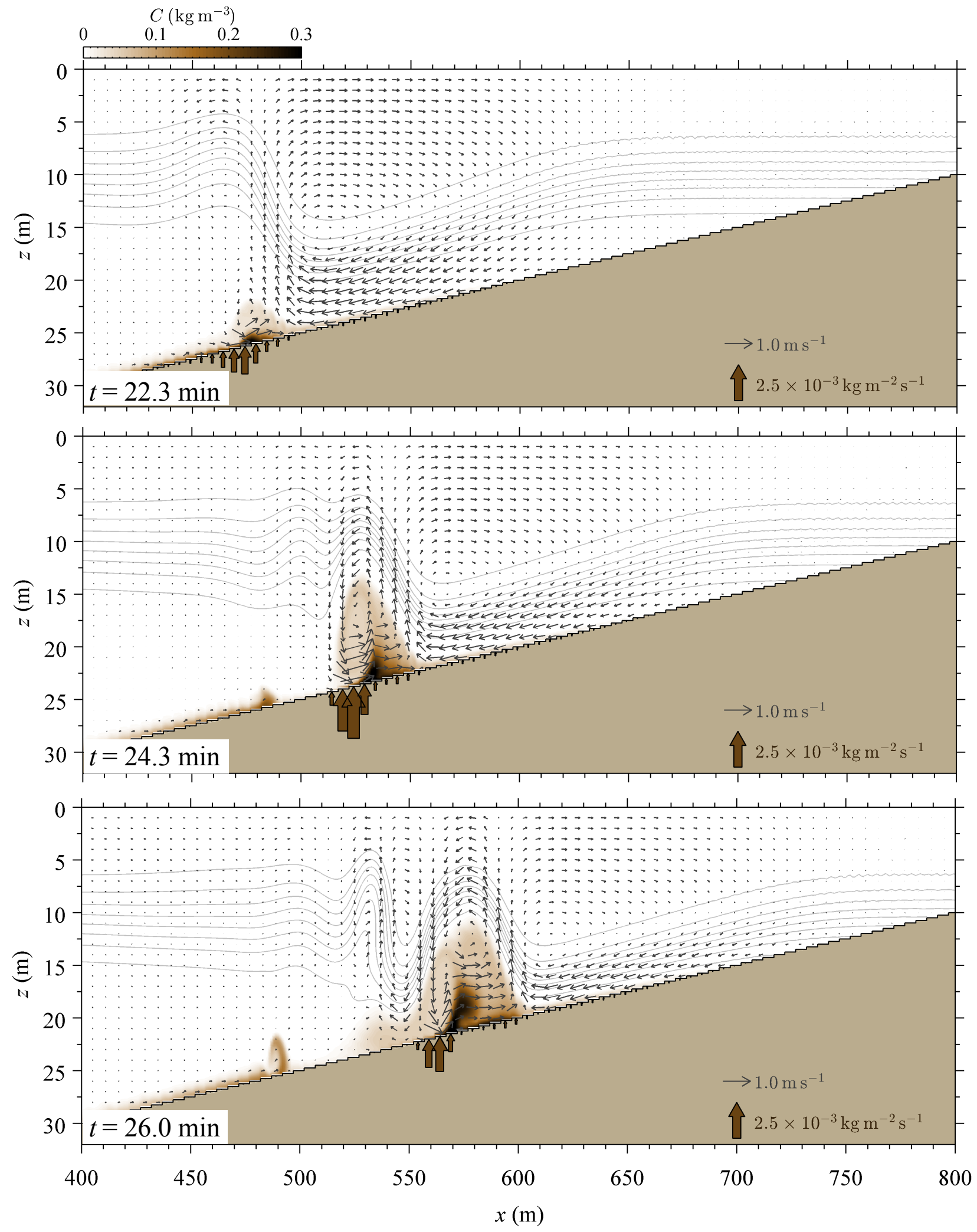

Figure 7: Details of the flow (black vectors), density (gray isolines $0.5 \mathrm{~kg} \mathrm{~m}^{-3}$ apart), sediment concentration (brown colorscale) and bottom sediment flux (brown vectors) within the time and spatial frames where most of the resuspension occurs (see text and Figures 5 and 6 for details). 

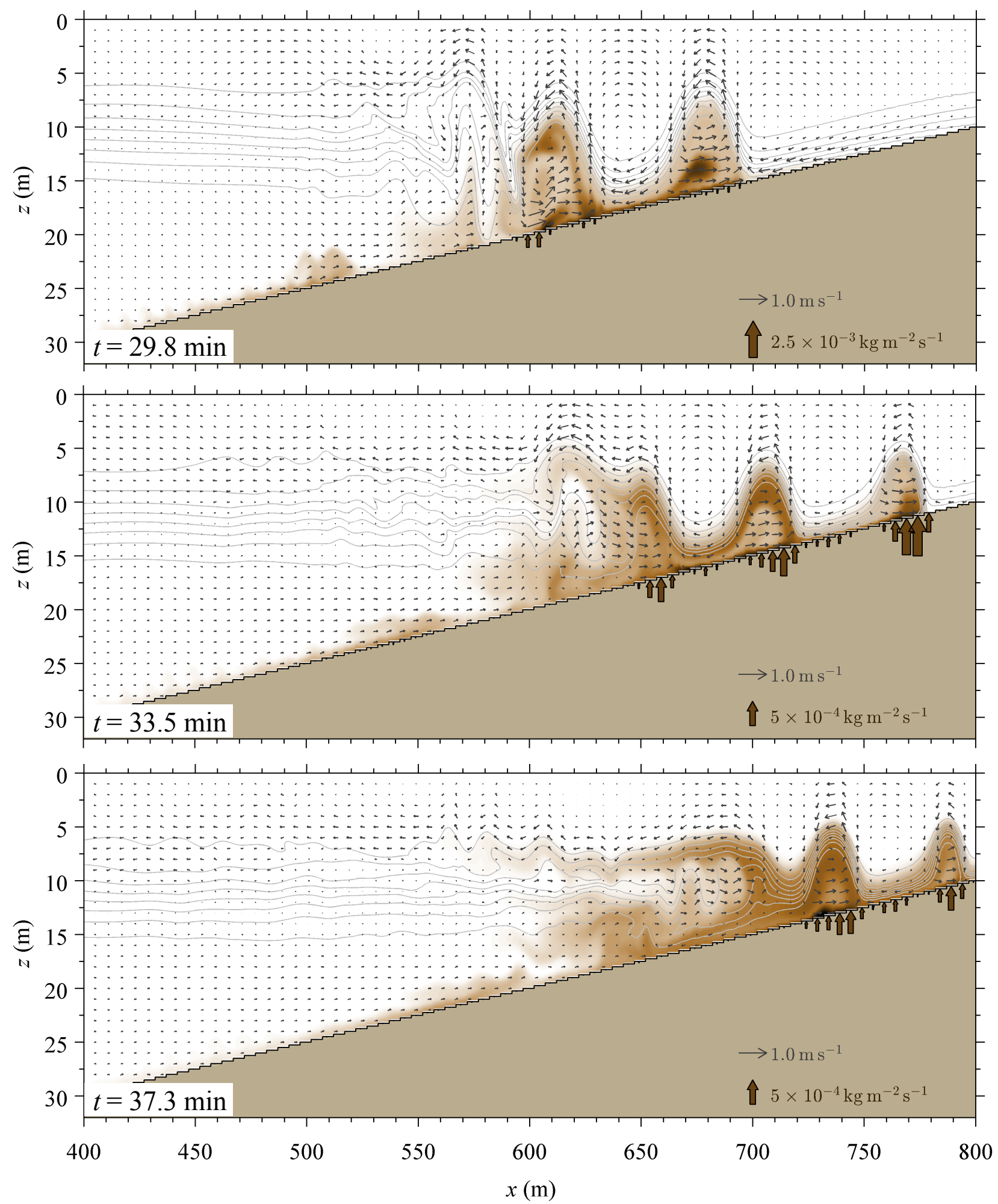

Figure 7: Continuation. Note the change in the scale of the bottom sediment flux in the last two panels. 

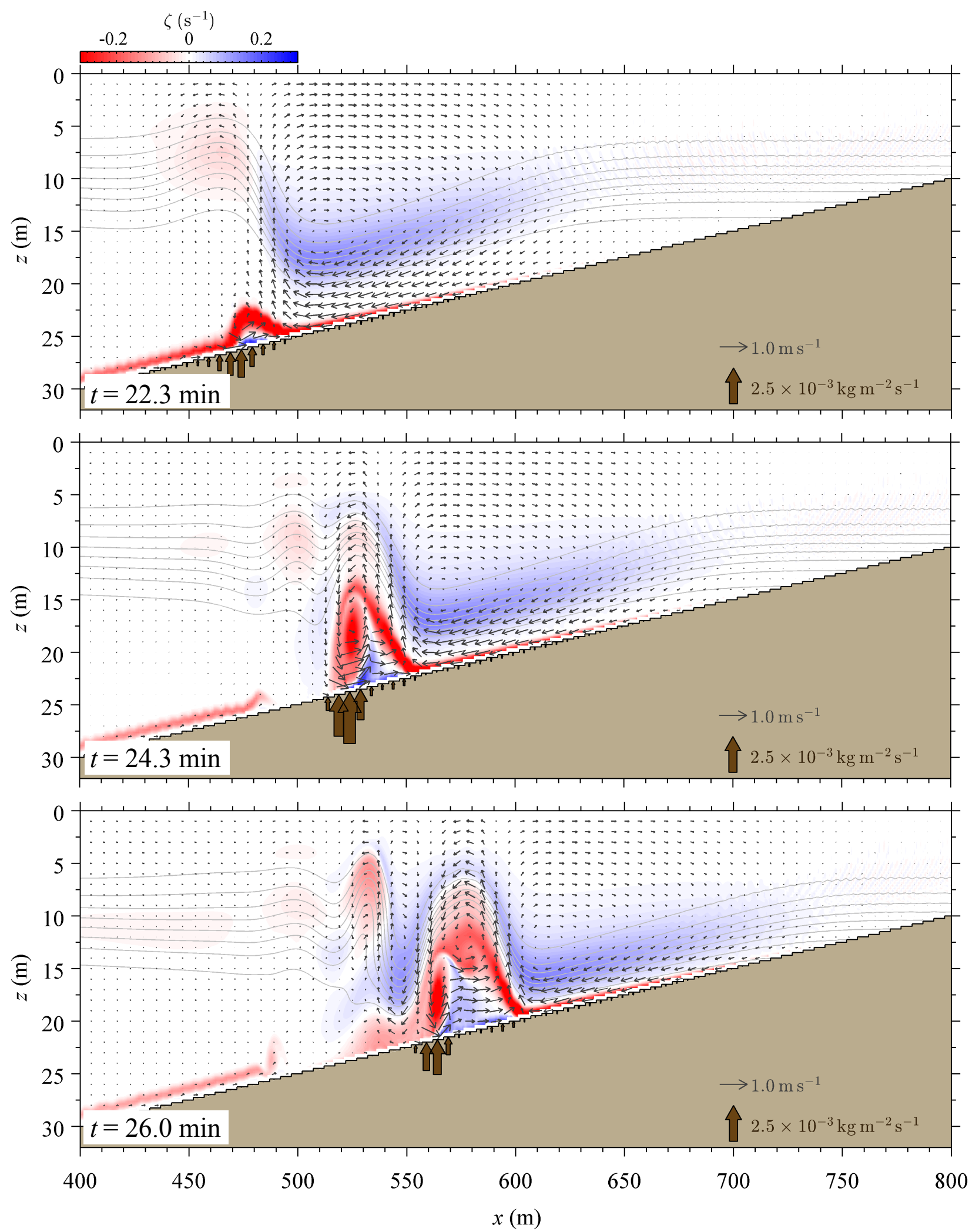

Figure 8: Details of the flow (black vectors), density (gray isolines $0.5 \mathrm{~kg} \mathrm{~m}^{-3}$ apart), vorticity (red-blue colorscale) and bottom sediment flux (brown vectors) within the time and spatial frames where most of the resuspension occurs (see text and Figures 5 and 6 for details). 


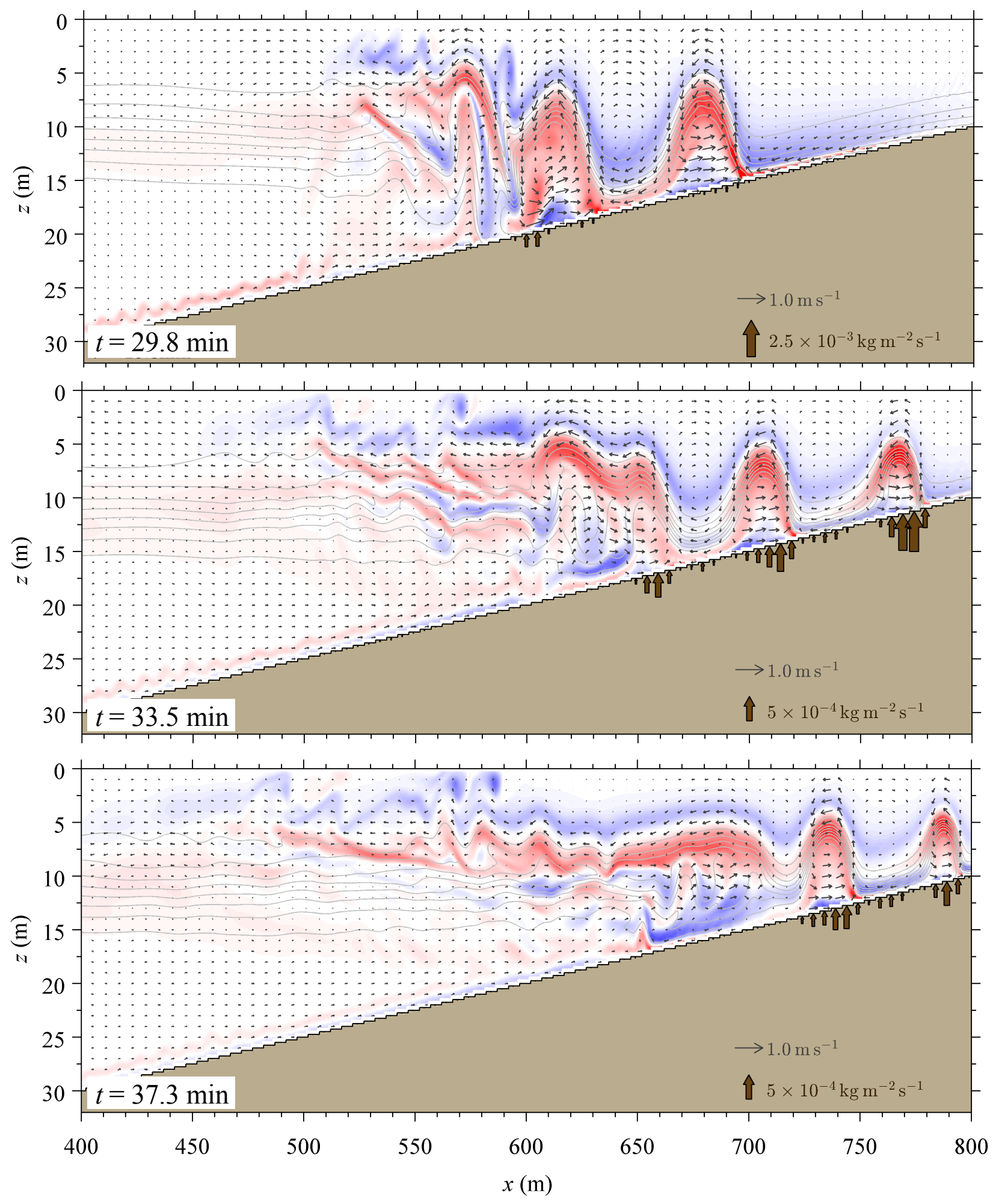

Figure 8: Continuation. Note the change in the scale of the bottom sediment flux in the last two panels. 


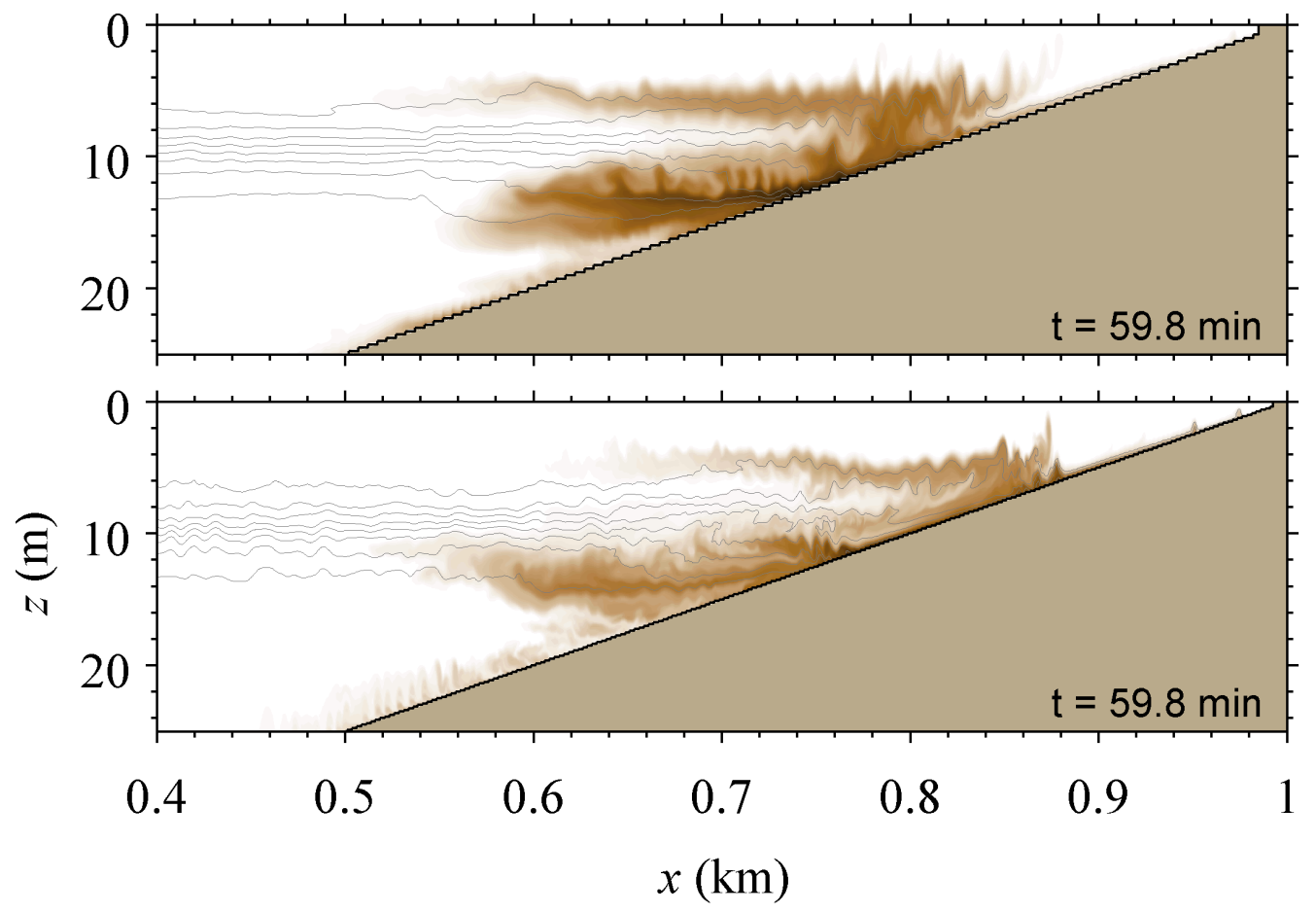

Figure 9: Sensitivity of resulting sediment concentration and distribution to grid resolution. (top) The standard grid with $\Delta x=1 \mathrm{~m}$ and $\Delta z=0.25 \mathrm{~m}$. (bottom) The high resolution grid with $\Delta x=0.5 \mathrm{~m}$ and $\Delta z=0.125 \mathrm{~m}$. 

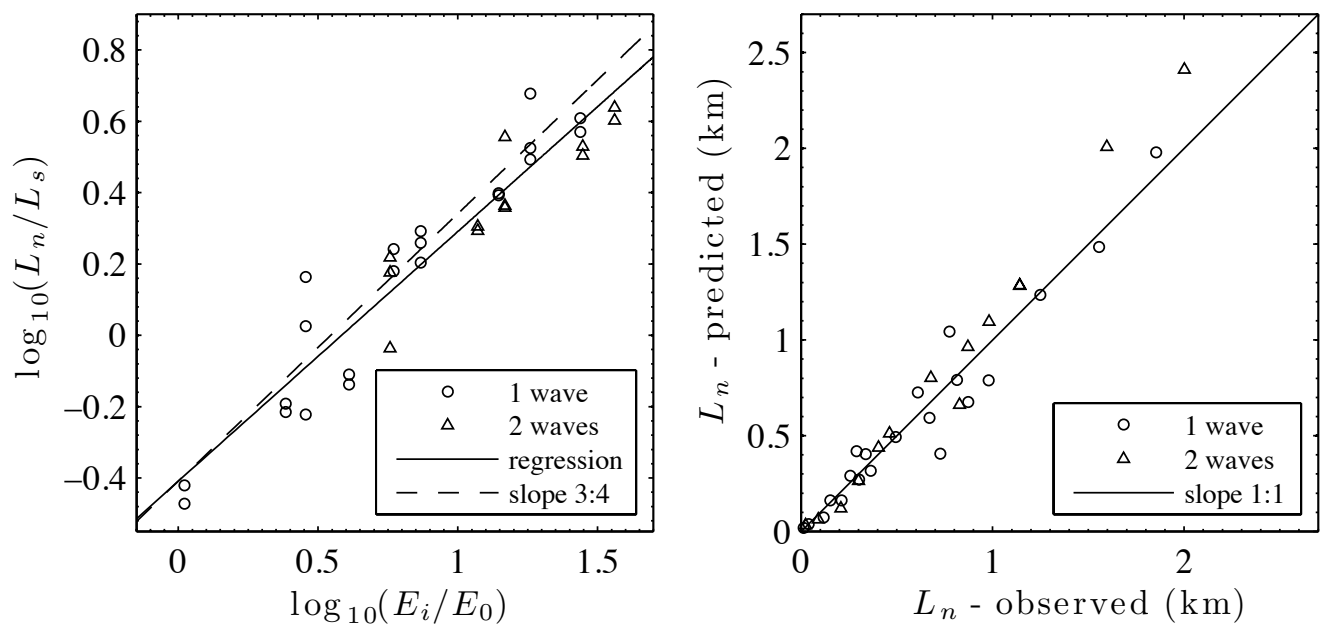

Figure 10: (Right) Variation of nondimensional excursion $\left(L_{n} / L_{s}\right)$ of intermediate nepheloids layers with nondimensional incident wave energy $\left(E_{i} / E_{0}\right)$, in $\log$ - $\log$ representation $\left(R^{2}=0.90, p<0.01\right)$. The regression slope is 0.70 with standard error 0.04. (Left) Comparisons between the predicted and observed (i.e. extracted from the model results) excursion length $L_{n}$ (see Equation 21). 


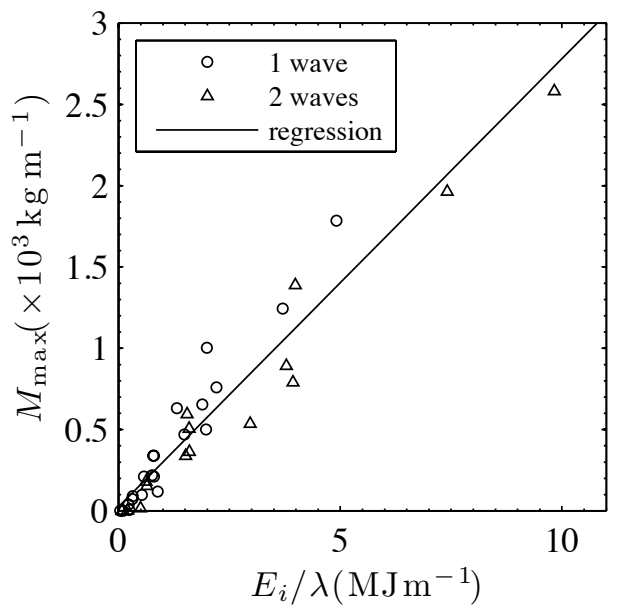

Figure 11: Maximum mass of suspended sediment $M_{\max }$ as a function of incoming wave energy weighted by $\lambda^{-1}=L_{s} / L$, i.e. the ratio of the length of the internal swash zone $L_{s}$ to the length of the incoming wave $L\left(R^{2}=0.93, p<\right.$ $0.01)$. 


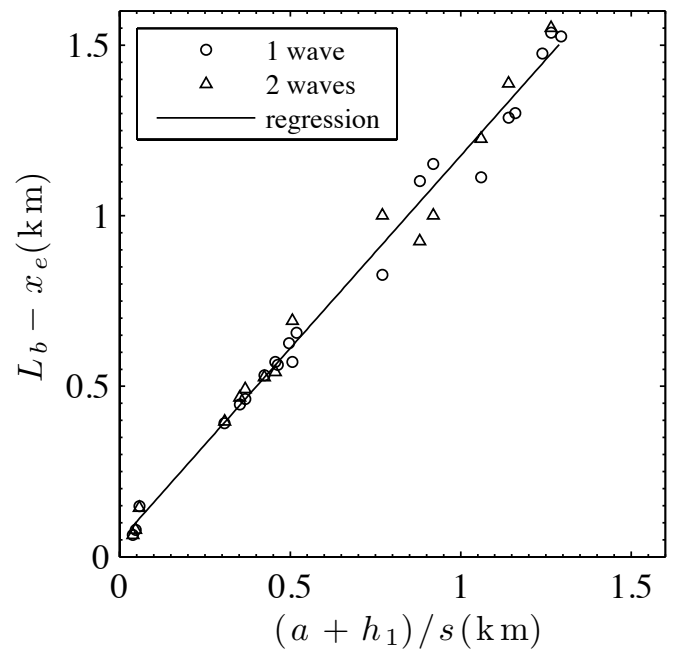

Figure 12: Horizontal distance from the shoreline of the point of maximum bed erosion (see definition of $L_{b}$ in Figure 2), as a function of the distance defined by $\left(a+h_{1}\right) / s\left(R^{2}=0.99, p<0.01\right.$, slope $\left.=1.13 \pm 0.04\right)$. 


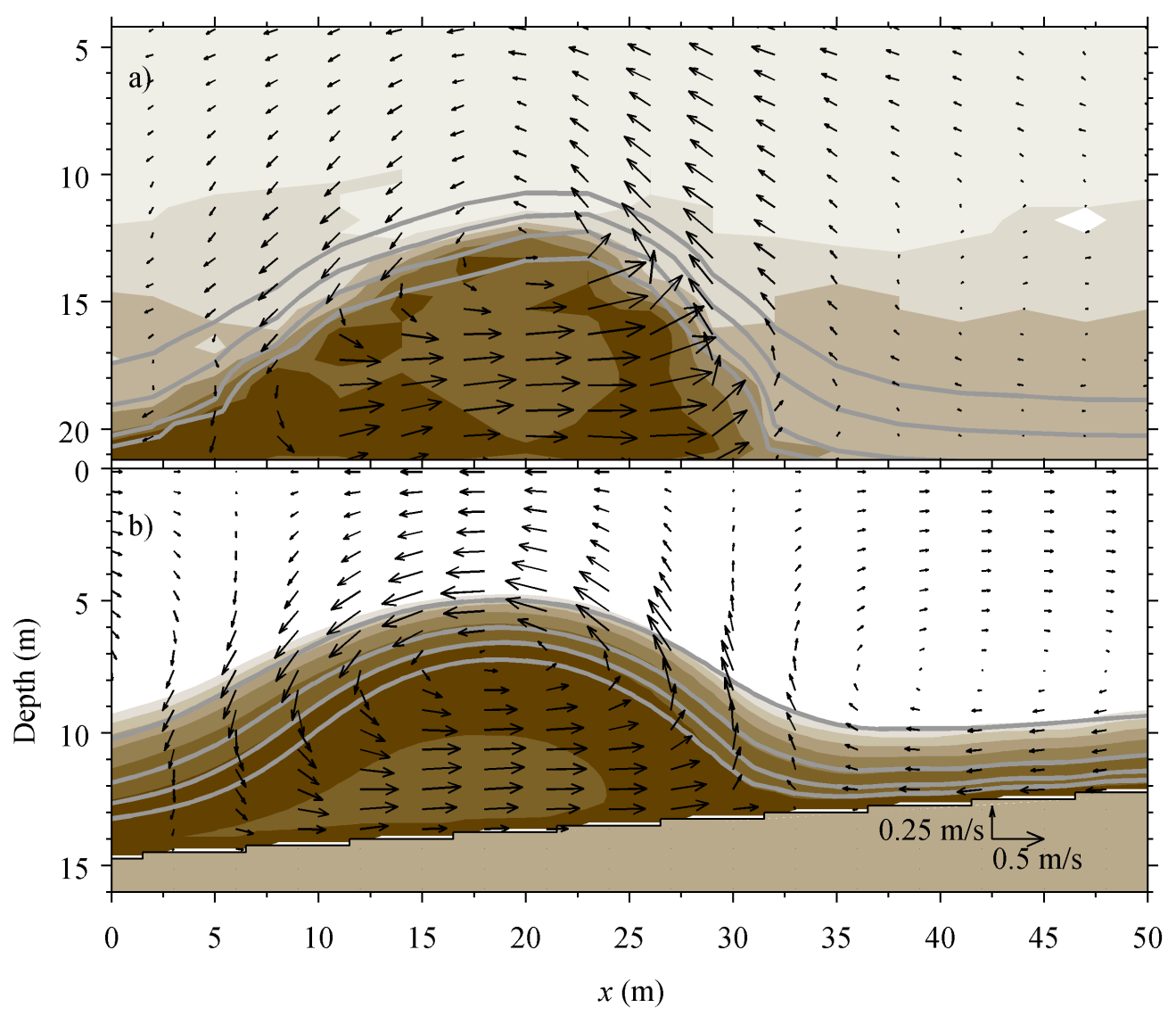

Figure 13: Qualitative comparison between (top) a bolus observed in the St. Lawrence Estuary (for more details on this particular bolus see Fig. 9 between 16:18-16:20 UTC in Richards et al., 2013) and (bottom) one simulated here (from run \#2). For the field observations, the colorscale represents acoustic backscatter (in $\mathrm{dB}$ ) collected from a moored acoustic Doppler current profiler and corrected for scattering losses along the beam transmit path. The data have therefore been collected through time but the figure has been constructed spatially by an estimation of the bolus phase speed. The colorscale for the model result is the logarithm of the sediment concentration. The colorscale ranges of both figures have been adjusted to look similar for this qualitative comparison. The comparison is relevant assuming that sediment concentration is correlated with acoustic backscatter. Contour lines are isopycnals in both cases. 